\title{
La apropiación de obras en el dominio público a través de su digitalización
}

\author{
The Appropriation of Public Domain Works \\ Through their Digitization
}

NICOLÁS BELLO LAGOS

Abogado independiente

RESUMEN En el presente artículo se estudia la apropiación de obras en el dominio público a través de su digitalización, examinando si esta conducta es lícita o no según los principios generales del derecho de autor. Para eso se revisan los dos grandes criterios de protección utilizados por esta rama: el sweat of the brow y la originalidad. A partir de ese análisis se revisa la protección de las fotografías, dado que la apropiación de obras en el dominio público se ha llevado a cabo principalmente a través de dicho medio. Además, se explica la diferencia entre las reproducciones y las obras derivadas, al ser las dos posibilidades que existen al momento de determinar la naturaleza jurídica de la versión digital de una obra. En el artículo se examina, además, la jurisprudencia de Estados Unidos. Por último, se revisa la situación en Chile para determinar si el país posee alguna posición sobre el tema.

PALABRAS CLAVE Derechos de autor, dominio público, digitalización, obras derivadas, reproducciones.

ABSTRACT In this article it's studied the appropriation of public domain works through their digitization, examining whether this conduct is per- 
missible or not according to the general principles of copyright. For this we examine the two main protection criteria used by this branch: the sweat of the brow and originality. Another analyzed theme is the protection of photographs, as the appropriation of public domain works is carried away mainly through this process. Also, it's explained the difference between reproductions and derivative works, being the two possibilities that exist when determining the legal nature of the digital version of a work. The article further examines the jurisprudence of the United States. Finally is analyzed the situation in Chile to determine if this country has any position in the issue.

KEYWORDS Copyright, public domain, digitization, derivative works, reproductions.

\section{INTRODUCCIÓN}

En 2009, un grupo de abogados de la National Portrait Gallery se contactó con la Fundación Wikimedia alegando la infracción —entre otras cosas- de los derechos de autor que la galería británica tenía sobre las reproducciones fotográficas de unas pinturas de su colección. ${ }^{\mathrm{I}}$ Wikimedia, que es una fundación sin fines de lucro responsable de proyectos como Wikipedia o Wikimedia Commons, sostuvo que las reproducciones no estaban protegidas por el derecho de autor, ya que eran copias de pinturas que se encontraban en el dominio público. Por tanto, podían hacer uso de ellas sin necesidad de solicitar permiso a la National Portrait Gallery. ${ }^{2}$ Este tipo de conducta, consistente en la apropiación de obras en el dominio público alegando tener derechos de autor sobre sus reproducciones, no es un fenómeno nuevo: se han documentado casos incluso desde antes de la invención de la fotografía.

El tema es relevante sobre todo con el surgimiento de nuevas tecnologías durante las últimas décadas, principalmente con la invención de

I. BBC, «Gallery in Wikipedia legal threat», disponible en <http://news.bbc.co.uk/2/ hi/entertainment/arts_and_culture/8I 5 I 989 .stm>.

2. Erik Moeller, «Protecting the public domain and sharing our cultural heritage», disponible en <http://blog.wikimedia.org/2009/07/I6/protecting-the-public-domain-andsharing-our-cultural-heritage/>. 
Internet. Las posibilidades que la red entrega en relación al acceso a las obras en el dominio público nos obliga a determinar la naturaleza de estas reproducciones debido a que es a través de ella que gran parte de la sociedad puede conocer dichas obras.

Los argumentos para aceptar o denegar la protección de reproducciones de obras en el dominio público se centran en dos criterios, el sweat of the brow y el requisito de la originalidad. Este tema ha sido desarrollado de forma extensa por la doctrina y jurisprudencia estadounidenses, las que conforman gran parte de la bibliografía utilizada en este artículo. Además del número de trabajos que se refieren al asunto que nos atañe, la posición estadounidense fue escogida por la importancia que dicho país tiene en la determinación de los alcances del derecho de autor en el ámbito mundial, sobre todo a través de tratados internacionales multilaterales y, en mayor medida, bilaterales de comercio. ${ }^{3}$

Se examinará también la situación en Chile con el fin de determinar los casos en los cuales nuestra legislación permite alegar la protección de este tipo de reproducciones.

\section{COPYFRAUD}

Las bibliotecas, archivos y museos tienen, en la gran mayoría de los casos, un derecho de propiedad sobre las obras que albergan. Son dueñas, por ejemplo, del bronce del que está elaborada una estatua, o del óleo y lienzo del que está hecha una pintura. Sin embargo, esta propiedad sobre sus componentes físicos no las hace titulares de los derechos de autor que puedan existir sobre las obras. Lo mismo ocurre, por ejemplo, al comprar un libro, lo que nos convierte en dueños de su soporte material, pero no de su contenido. La distinción entre ambas figuras es evidente en el caso de obras que se encuentran en el dominio público, donde no existen derechos de autor que las protejan, pero los materiales de las que están hechas sí son propiedad de la institución que las alberga. Así, la

3. No se puede negar la influencia que el país norteamericano tuvo en las reformas realizadas a la Ley de Propiedad Intelectual chilena desde el año 2003 en adelante. El Tratado de Libre Comercio celebrado entre Chile y Estados Unidos fue una de las razones para llevar a cabo dichas reformas, las cuales tenían como objetivo adecuar la regulación nacional a los parámetros del instrumento bilateral. Cf. Álvarez Valenzuela (20I I). 
Mona Lisa, al ser una pintura que fue creada hace siglos, no está protegida actualmente por el derecho de autor, y el Museo del Louvre sólo tiene sobre ella un derecho de propiedad respecto de su expresión tangible. Ilustremos esto con un ejemplo:

Un visitante del archivo que roba la obra y hace copias de ella en su casa, o que cuela un dispositivo de grabación en el archivo, podría enfrentar acciones legales: hurto, por ejemplo, o el incumplimiento de un acuerdo de acceso firmado con el archivo. Pero [...] no se ha producido una violación de derechos de autor (Mazzone, 2006: 1058).

La diferencia que existe entre el derecho de autor y el derecho de propiedad sobre la materialidad de la obra no es siempre reconocida, existiendo algunos esfuerzos por hacer pasar como obras protegidas aquellas que no lo están. Esta conducta que consiste en «alegar falsamente un derecho de autor sobre una obra que está en el dominio público» ha sido denominada por Jason Mazzone como copyfraud (Mazzone, 2006: I028). El término que utiliza este autor estadounidense es un acrónimo que combina las palabras copyright y fraud («fraude» o «estafa», en inglés). El copyfraud puede ser cometido de diversas formas; una de ellas es la publicación de trabajos que están en el dominio público, como la obra de Miguel de Cervantes o Alonso de Ercilla, agregando en los ejemplares de sus libros que su contenido no puede ser reproducido sin autorización del titular de los derechos.

Otra forma de copyfraud consiste en la apropiación de obras en el dominio público a través de sus reproducciones. Aunque la obra reproducida se encuentra en el dominio público, se ha sostenido durante años que sus reproducciones están sujetas a derecho de autor, ya que constituirían una obra distinta de la original. La digitalización de patrimonio cultural que se ha llevado a cabo durante los últimos años sirve como ejemplo de esta conducta.

La digitalización consiste en copiar (reproducir) un objeto preexistente a través de procesos como el escaneo o la fotografía, con el fin de generar un archivo digital que sirva como representación fiel del objeto análogo. Con la digitalización se busca asegurar el acceso a las obras y preservarlas de mejor manera.

Al visitar los sitios web de museos, bibliotecas y archivos, se puede notar que en sus términos de uso, o al final de la página, se menciona que 
todo el contenido es de propiedad de la institución en cuestión. A modo de ejemplo, el Museo Nacional del Prado señala en su portal web: «Se prohíbe cualquier acto de reproducción total o parcial de los contenidos, en cualquier forma o medio (mecánico, electrónico, reprográfico o de cualquier otro tipo), así como cualquier acto de difusión, comunicación pública o distribución, sin la previa autorización por escrito del Museo Nacional del Prado o de sus legítimos propietarios».4 Tal prohibición, que de por sí es excesivamente restrictiva al no contemplar las excepciones al derecho de autor que recogen las leyes del país, abarca no sólo a las obras que son creadas por el museo, como el diseño del sitio web, el conjunto de las obras a modo de compilación, o artículos escritos por sus investigadores, sino también las reproducciones de obras en el dominio público que alberga dicha institución. Con esto se sostiene, por ejemplo, que la versión digital de Las meninas no puede ser utilizada sin antes solicitar permiso al museo, aun cuando Diego Velázquez haya fallecido en I 660 y los derechos de autor que recaían sobre la pintura ya caducaron. Algo similar realiza la Biblioteca Nacional de España, que en una de sus guías para la digitalización de archivos exige, como paso esencial en el proceso, agregar en el archivo una marca de agua que indique lo siguiente: «(C) Biblioteca Nacional de España».5

La situación en Chile no es distinta. El portal Artistas Plásticos Chilenos, desarrollado por la biblioteca del Museo Nacional de Bellas Artes, tiene al final de la página un aviso que reza: «(C) Derechos Reservados, Museo Nacional de Bellas Artes». ${ }^{6}$ Si bien se menciona la posibilidad de reproducir total o parcialmente los textos publicados en el sitio, no se hace referencia alguna a las reproducciones digitales que alberga, muchas de las cuales pertenecen al dominio público por ser pinturas de artistas que fallecieron hace varias décadas, ${ }^{7}$ como Alfredo Valenzuela Puelma o

4. Museo Nacional del Prado, «Aviso legal», disponible en <http://www.museodelprado.es/aviso-legal/>.

5. Biblioteca Nacional de España, «Proceso de digitalización en la Biblioteca Nacional de España», p. I7, disponible en <http://www.bne.es/es/Catalogos/BibliotecaDigital/ docs/ProcesoDigitalizacionBNE_IooI 20I I_version3.pdf $>$.

6. Museo Nacional de Bellas Artes, «Artistas Plásticos Chilenos», disponible en $<$ http://www.artistasplasticoschilenos.cl/>.

7. Actualmente la Ley de Propiedad Intelectual chilena establece que la protección de las obras dura por toda la vida del autor y se extiende hasta los 70 años siguientes a su falle- 
Pedro Lira. Esta omisión es relevante, ya que un aviso tan general como el mencionado hace concluir que las reproducciones digitales también estarían sometidas a derechos reservados del museo. La conducta se repite en el catálogo fotográfico digital del Museo Histórico Nacional, en cuya página se puede leer un aviso que señala lo siguiente: "Copyright (C) 20I0. All Rights Reserved». Al visualizar las fotografías digitalizadas que alberga el catálogo, «las cuales fueron en su mayoría tomadas durante las primeras décadas del siglo XX», el museo ha agregado una marca de agua digital al medio de la fotografía que dice «Archivo Fotográfico Museo Histórico Nacional», limitando o entorpeciendo así su utilización. ${ }^{8}$

La apropiación de obras en el dominio público obedece, entre otros motivos, a un factor económico. Dado que las obras de arte tienen una naturaleza única, lo normal es que sólo exista un ejemplar de cada una. Por lo tanto, las reproducciones, principalmente fotográficas, son esenciales para que personas como profesores, editores, publicistas y público en general, puedan utilizar tales obras. Al existir una demanda, diversos agentes económicos comenzaron a ofrecer licencias de uso respecto de reproducciones de obras de arte. Uno de estos agentes es Corbis, empresa creada por Bill Gates en I989, la cual posee una vasta librería de reproducciones digitales de obras albergadas en galerías a lo largo del mundo. Su giro consiste en vender licencias de uso respecto de las reproducciones digitales por un período determinado de tiempo. Para proteger sus imágenes, Corbis emplea diversos métodos; uno de ellos es alegar que tales reproducciones digitales están protegidas por el derecho de autor (Cooper, 20II: 9-I6).

\section{EL OBJETIVO DEL DERECHO DE AUTOR}

La protección otorgada por el derecho de autor se ha justificado a través de diversas teorías. La primera de ellas sostiene que al garantizar dere-

cimiento. Este plazo ha ido aumentando de forma paulatina, ya que con anterioridad se extendía hasta los 50 años siguientes al fallecimiento, y antes de eso hasta los 30 años. Una explicación más detallada se puede ver en Daniel Álvarez, «Autores en el dominio público chileno", disponible en <http://www.simenon.cl/autores-en-el-dominio-publico-chileno/>.

8. Museo Histórico Nacional, «Catálogo fotográfico digital», disponible en <http:// www.fotografiapatrimonial.cl/>. 
chos exclusivos al autor se está incentivando la creatividad, ya que esta «recompensa» lo llevará a hacer nuevas creaciones. Una segunda teoría, basada algunas veces en el derecho natural, establece que toda persona tiene un derecho de propiedad sobre los frutos de su trabajo, lo que también debería aplicarse en el caso de las creaciones intelectuales (Unesco, 20I0: IO-II). Esta posición, que fue sostenida por el filósofo John Locke, establece que: «en la medida que un autor incorpora su trabajo para la creación de una obra se apropia de la obra y la justificación de esta apropiación no se encuentra sino en la relación existente entre el autor y la obra» (De la Maza, 2006: 64). Una tercera concepción, que surge con la obra Filosofía del derecho de Hegel, sostiene que la propiedad es necesaria como atributo de la personalidad, debido a que los individuos deben tener cierto control sobre los recursos que los rodean. Una última teoría, denominada «democrática», evita centrarse en la figura del autor como lo hace la concepción de Locke, optando por atender a las consecuencias sociales que surgirían a partir de un determinado régimen de propiedad intelectual. A diferencia de la primera teoría, que apunta a un aspecto más económico, la concepción democrática busca «la promoción de la educación pública y la diversidad expresiva» (De la Maza, 2006: 64-67).

Independiente de la teoría que se adopte, se ha dicho que «los regímenes de propiedad intelectual confieren expresión legal a los derechos morales y económicos de los creadores en lo que respecta a sus creaciones» (Chapman, 200I: 8). Sin embargo, ver al derecho de autor sólo como la protección que recibe una persona por su labor intelectual es ver el tema de forma incompleta. Se ha señalado que el objetivo del derecho de autor consiste en obtener un equilibrio entre lo privado y lo público, es decir, entre los autores y la sociedad (Ruiz Gallardo, 20го: 5). Así, es necesario que garantice ciertos derechos exclusivos en beneficio del autor de una obra determinada, pero cuidando que tales derechos no sean de tal magnitud que impidan a la sociedad la utilización de la obra. Es por esto que tratados internacionales y leyes nacionales han reconocido una serie de excepciones y limitaciones a esta protección con el fin de asegurar un beneficio para la sociedad. La Unesco ha sostenido que «la interrelación entre los derechos exclusivos, por un lado, y las excepciones y limitaciones a estos derechos, por el otro, constituye el marco jurídico en el que la creatividad y la comunicación se pueden desarrollar»(Unesco, 20I0: Io). 
Según Audrey Chapman, esta necesidad de equilibrio entre ambas posiciones surge al asumir un enfoque de la propiedad intelectual como un derecho humano y no como un mero concepto de carácter económico. Esto, ya que un enfoque de derechos humanos exige tener en cuenta aspectos como el bien común, la dignidad humana y el bienestar de la sociedad, lo que impediría el otorgamiento de derechos exclusivos e irrestrictos a los autores en desmedro de los usuarios (Chapman, 200I: I 5). Por lo tanto, privilegiar la protección de los derechos de los autores en forma excesiva generaría efectos negativos en la sociedad, como un aumento en los costos que terminaría afectando actividades como la investigación científica (Chapman, 200I: 27).

Este interés público al momento de hablar del tema ha sido reconocido por la Constitución de Estados Unidos, que sostiene que el objetivo del derecho de autor es "promover el progreso de las ciencias y de las artes útiles». Además, se puede ver en el denominado Estatuto de la Reina Ana, que fue dictado en I7 Io en el Reino Unido, y que prescribía que el objetivo del derecho de autor consistía en «fomentar el aprendizaje» (IFLA, 200I: 2). La existencia de estos dos aspectos, lo privado y lo público, también fue reconocida en I 948 por la Declaración Universal de Derechos Humanos, que en su artículo 27 señala:

I. Toda persona tiene derecho a tomar parte libremente en la vida cultural de la comunidad, a gozar de las artes y a participar en el progreso científico y en los beneficios que de él resulten.

2. Toda persona tiene derecho a la protección de los intereses morales y materiales que le correspondan por razón de las producciones científicas, literarias o artísticas de que sea autora.

Similares derechos fueron reconocidos en la Declaración Americana de los Derechos y Deberes del Hombre de 1948, así como en el Pacto Internacional de Derechos Económicos, Sociales y Culturales de I966 (Lipszyc, 2005: 38). La Constitución Política de Chile — tras la reforma constitucional del año 200I (Ley I9.742) — también reconoce estos derechos, si bien de forma menos clara: «[La Constitución asegura a todas las personas] la libertad de crear y difundir las artes, así como el derecho del autor sobre sus creaciones intelectuales y artísticas de cualquier especie, por el tiempo que señale la ley y que no será inferior a la vida del 
titular». ${ }^{9}$ Es esta libertad de difundir las artes la que constituye el contrapeso a la protección que tiene el autor sobre sus obras, logrando -al menos en esta disposición - el ya mencionado equilibrio que debe existir entre ambos conceptos (Ruiz Gallardo, 2008: 37).

Sin embargo, durante las últimas décadas este equilibrio se ha visto afectado por una creciente y sostenida sobreprotección del derecho de autor. Así, este derecho que en un principio se limitaba a garantizar actividades exclusivas, como la reproducción y comunicación pública, se ha extendido a otras conductas, como la distribución, modificación y adaptación de las obras. A esto se suma el aumento del plazo de protección, que debido a la constancia con que se ha llevado a cabo, ha ido transformando el límite temporal del derecho de autor en una mera enunciación (Ruiz Gallardo, 2008: 32-33). Este desequilibrio no tiene sólo una relevancia conceptual, sino que implicancias prácticas, dando lugar a tres grandes riesgos: «inhibe la producción de nuevas obras, limita en forma excesiva la expresión de opiniones disidentes y, por último, mina en forma fundamental la salud del discurso público» (Ruiz Gallardo, 2008: 34).

\section{DOMINIO PÚBLICO}

El dominio público, denominado «patrimonio cultural común» en nuestro país, es el conjunto de obras que no posee protección por parte del derecho de autor, sea porque nunca la ha tenido o debido a que ha expirado el término de protección que la ley le otorgó (Cerda, 20 I I: 255). En el primer caso se encuentran aquellas obras que no cumplen con los requisitos exigidos por la ley para ser protegidas como, por ejemplo, las meras ideas. También están aquellas obras que según la legislación interna de cada país no están protegidas, como el caso de las obras creadas por organismos gubernamentales en Estados Unidos, o las obras de autor desconocido (mientras permanezca desconocido), en el caso de Chile.

En el segundo grupo de obras que están en el dominio público se encuentran aquellas que, no obstante haber cumplido con los requisitos

9. Constitución Política de la República, art. I9 núm. 25. La Ley I9.742 de 200 I incluyó la frase «la libertad de crear y difundir las artes», ya que con anterioridad sólo se aseguraba el derecho del autor sobre sus creaciones intelectuales y artísticas. 
para ser protegidas por el derecho de autor, pierden dicha protección una vez transcurrido el término que la ley señala. Dichas obras ya han gozado de protección por un número determinado de años, luego de los cuales expiran los derechos de su titular (Cerda, 20I I: 256). La protección de las obras no puede ser perpetua y el plazo variará según cada país; actualmente en Chile, 70 años tras la muerte del autor. Entre las razones esgrimidas para explicar esta protección limitada en el tiempo se encuentra la dificultad de identificar a los herederos del autor una vez transcurrido cierto tiempo. Una protección perpetua tornaría difícil pedir permiso para utilizar una obra, ya que no se tendría claridad acerca de quiénes son los titulares de los derechos. Otra explicación para la protección temporal de los derechos de autor viene dada por la naturaleza de las obras en cuestión, que pueden ser poseídas y utilizadas por un gran número de personas al mismo tiempo. Además, como ha señalado la Organización Mundial de la Propiedad Intelectual (OMPI), la utilización y posesión de tales obras «están al servicio de importantes objetivos sociales, como la educación, la investigación, la información, el entretenimiento, etcétera. Las obras más valiosas y más resistentes al paso del tiempo pueden llegar a ser patrimonio común de una nación o de toda la humanidad» (Ficsor, 2003: 48). Se ha señalado también que dado que los autores aplican elementos que se encuentran en el patrimonio cultural colectivo para sus propias creaciones, «es justo que éstas, a su turno, también vayan a integrar ese fondo común» (Lipszyc, 2005: 250).

La importancia del dominio público puede ser examinada desde dos puntos de vista: uno que se centra en su relevancia social y otro en su importancia utilitarista o económica. El primero considera que el dominio público es «un requisito fundamental para la autoría, la libertad de expresión y, por tanto, el diálogo democrático» (Dobusch, 20 I I: 6). Según Jessica Litman, todos los trabajos de autoría poseen elementos adaptados de obras preexistentes, por lo que la existencia del dominio público es fundamental. Para la autora, lo relevante del dominio público no es la ausencia de protección que tienen dichas obras, sino su calidad de materia prima que está a disposición de los autores (Dobusch, 20I I: 7-8). Por ende, las creaciones intelectuales no pueden ser entendidas de forma aislada, ya que se encuentran insertas «en uno o más sectores del conocimiento de la humanidad». Estas creaciones son realizadas aprovechando los descubrimientos y avances que llevaron a cabo generaciones 
previas de artistas y científicos (Schmitz Vaccaro, 2009: 347). Una idea similar fue tratada en el documental Everything is a Remix de Kirby Ferguson, donde se hace referencia a una famosa frase que ha sido atribuida (erróneamente) a Isaac Newton: "Somos como enanos en hombros de gigantes». La frase se refiere a cómo los descubrimientos y el conocimiento surgido en el pasado sirven como base para los descubrimientos venideros. En el documental se hace una analogía con la forma en que las ideas y elementos desarrollados en el arte son reciclados o usados como base en obras posteriores. ${ }^{\text {I0 }} \mathrm{El}$ tema ha sido también examinado por Lawrence Lessig, quien señala:

Los creadores en este país y en cualquier sitio siempre y en todo momento se basan en la creatividad que vino antes y que los rodea ahora [...] [todas las sociedades] han dejado partes de su cultura libres para que se tomen para otras obras -las sociedades libres de una forma más completa que las no libres, pero todas las sociedades en algún grado [...]. Las culturas libres son culturas que dejan una gran parte abierta a los demás para que se basen en ella; las que no son libres, las culturas del permiso, dejan mucho menos (Lessig, 2005: 38 ).

Por otro lado, la relación del dominio público con la libertad de expresión ha aumentado con el surgimiento de nuevas tecnologías, particularmente con Internet. El cambio de circunstancias que ha generado la revolución tecnológica de los últimos años no hace aconsejable aplicar los principios del derecho de autor sin antes adaptarlos a este nuevo modelo. Un ejemplo de esto es la dificultad que existe al momento de distinguir entre utilizar y reproducir una obra digital, como un libro electrónico o un archivo de audio. Por lo tanto, el dominio público se está haciendo cada vez más importante al momento de "conservar las formas básicas de utilización e interacción con el contenido» (Dobusch, 2OII: II).

El derecho de autor debe buscar un balance entre la protección de la autoría y la protección de la libertad de expresión. ${ }^{\text {II }}$ El panorama

Io. Kirby Ferguson, Everything is a Remix. Part 2, disponible en <http://vimeo. com/I9447662>.

I I. Según Jason Mazzone, este balance se rompe cuando ciertas instituciones interfieren con el uso de materiales en el dominio público (Mazzone, 2006: I059). 
actual evidencia una clara inclinación hacia la protección de la autoría, lo que torna complejo un efectivo ejercicio de la libertad de expresión. El constante aumento de los plazos de protección, sumado a un sistema que dificulta la identificación de los verdaderos titulares de los derechos de autor, "fuerza a muchos al silencio cuando, de otra forma, podrían hablar» (Lessig, 2005: 23I).

Desde un punto de vista utilitarista y económico, un dominio público fuerte es «necesario para permitir la competencia y la innovación en el ámbito económico» (Dobusch, 20II: 7). Esta afirmación está relacionada con la distinción entre ideas y formas de expresión. Dado que las meras ideas no pueden ser protegidas a través del derecho de autor, se permite que una misma idea pueda ser expresada por diversas personas a la vez, cuidando que dichas formas de expresión no sean idénticas entre sí (Dobusch, 20II: I3). Prohibir esto crearía un monopolio que haría difícil una economía competitiva, dado que el primero que emplee una determinada idea obtendría un poder que impediría a los demás utilizarla, incluso a través de otras formas de expresión.

La importancia del dominio público ha sido entendida por numerosas organizaciones, sobre todo en Internet. Proyectos como Communia, ${ }^{12}$ Internet Archive, ${ }^{\mathrm{I} 3}$ The Public Domain Review ${ }^{\mathrm{I} 4}$ o Europeana ${ }^{\mathrm{I} 5}$ se encargan de educar acerca del rol que cumple el dominio público en la sociedad y alertan sobre las amenazas que afectan a este tipo de obras. Una de las amenazas al dominio público, como ya se mencionó, es la apropiación que se hace de este tipo de obras al alegar tener derechos de autor sobre sus versiones digitales. Según Beatriz Busaniche, de Wikimedia Argentina, «la sociedad está tomando decisiones que restringen la libre circulación de la información y las ideas justo en el momento en que la disponibilidad de tecnologías habilitan una difusión y aprovechamiento como nunca antes fue posible» (Busaniche, 20I I: 9).

I2. Communia, The European Thematic Network on the Digital Public Domain, $<$ http://www.communia-project.eu/>.

I3. Internet Archive, <http://archive.org/index.php>.

I4. The Public Domain Review, <http://publicdomainreview.org/>.

I 5. Europeana, <http://www.europeana.eu/>. 


\section{DIGITALIZACIÓN}

La digitalización o conversión analógica-digital es un proceso a través del cual se traspasa una señal desde un soporte análogo a uno digital. Es decir, "consiste en trasformar muestras de la misma en series de impulsos binarios o secuencias de ceros y unos (bits), de manera que si el número de muestras es suficiente, permite una réplica perfecta del original». El resultado es un código binario que al ser leído por una máquina (un computador) genera una réplica de la información que fue transmitida (Artaza Castro, 2003: I3). Por ejemplo, el escaneo que se hace de un dibujo genera un archivo digital que emula a la perfección la imagen que fue digitalizada. El sensor del escáner utilizado registra la imagen del documento en cuestión y el resultado es un archivo digital, una cuadrícula dividida en puntos o píxeles que tendrán un determinado valor binario, dependiendo de la luminosidad y tono lumínico leído por el dispositivo (cf. Archivos de Castilla y León, 20 I : 8).

Una de las características de esta copia digital es que puede servir de base para realizar otras copias de idéntica calidad: «La copia un millón de una obra fijada en formato digital es tan perfecta como la primera, y puede servir de base para posteriores reproducciones, sin disminución o desgaste de la calidad de la obra reproducida» (Artaza Castro, 2003: I4), a diferencia de las fotocopias, donde las copias que se hagan de las versiones fotocopiadas van disminuyendo en calidad. Otras características de estas versiones digitales son su bajo costo y la rapidez con que pueden ser realizadas. La digitalización facilita también la difusión de las obras, sobre todo a través de Internet. Las obras pueden, por lo tanto, ser comunicadas de forma inmediata y a un número ilimitado de personas, lo que no resultaba sencillo en el caso de las obras materiales. Además, «una obra al ser transmitida a otras personas, les permite obtener una copia idéntica a la del transmisor, sin que éste tenga que desprenderse de su ejemplar» (Artaza Castro, 2003: I 5). Incluso, al ser traspasadas a un formato digital, las obras pasan a estar en un formato único, a diferencia de lo que ocurre en sus versiones análogas, donde son fácilmente diferenciables las pinturas de los libros, o las películas de las esculturas. Este nuevo estado permite «la combinación de obras de distinta naturaleza en un mismo soporte, facilitando su almacenamiento, transmisión y recuperación como producto unitario» (Artaza Castro, 2003: I4-I 5). 
De lo anteriormente dicho se pueden identificar varias formas de digitalización, dependiendo del tipo de obra que sirve como base. En primer lugar, es una digitalización el escaneo que se realice de alguna imagen que se encuentre en una superficie plana, como documentos, libros, dibujos, planos arquitectónicos, partituras o fotografías. Lo que se hace en tal caso es tomar la imagen bidimensional, ubicarla en un dispositivo llamado escáner y éste realiza a través de un haz de luz o láser una captura de la obra y transfiere la imagen al computador. Para el caso de documentos o libros es preciso hacer algunas aclaraciones. Dado que el escáner sólo transfiere una imagen del objeto en cuestión, es necesario procesar el archivo resultante para que el texto que contiene sea identificado. Dicho proceso es denominado optical character recognition (OCR), y a través de él la máquina reconoce de forma óptica los caracteres o símbolos que componen el documento. ${ }^{16}$ La digitalización de un libro o documento, por lo tanto, puede realizarse de ambas formas, ya sea a través de la transferencia de la imagen o del texto en sí. Además, se puede señalar que la transcripción que se haga manualmente de un libro al computador también es una digitalización, ya que lo relevante es el contenido del mismo, las palabras.

En el caso de obras plásticas bidimensionales de mayor tamaño, como pinturas o murales, el proceso de digitalización es más complejo. Dado que los escáneres tienen un tamaño menor al de estas obras, la forma más práctica de digitalizarlas es a través de la fotografía. Ya que el proceso de fotografía de obras de arte es más complejo que el escaneo, surgen algunas dudas sobre la posible protección del esfuerzo invertido, lo que será examinado más adelante.

Mayor complejidad reviste el caso de obras tridimensionales, como las esculturas. Como se señalará más adelante, la fotografía de este tipo de obras no las captura en su totalidad, sino que simplemente una porción de ellas. Por lo tanto, es difícil hablar de digitalización de obras tridimensionales a través de este método. No obstante aquello, el avance tecnológico ha permitido que estos inconvenientes sean superados, permitiendo la digitalización total de tales obras. Hoy en día existen escáneres que permiten registrar los datos de la superficie de objetos tridimensionales, generando un archivo en tres dimensiones del mismo. Un

I6. Alegsa, definición de OCR disponible en <http://www.alegsa.com.ar/Dic/ocr.php>. 
ejemplo de esto se puede ver en la industria del cine, donde la tecnología ha permitido que el rostro de los actores pueda ser registrado a través de cámaras especiales y posteriormente digitalizado, produciendo un archivo digital en tres dimensiones que permite su modificación por parte de los artistas encargados de los efectos especiales.

La digitalización de materiales audiovisuales consiste básicamente en escanear los fotogramas que componen la película, traspasando la imagen a un formato digital. ${ }^{17}$ Los fotogramas corresponden a las imágenes que componen la película, las que al ser mostradas con una determinada continuidad y velocidad (aproximadamente 25 fotogramas por segundo) generan la sensación de movimiento (Petris, 2003: I). La digitalización del sonido, por su parte, se lleva a cabo mediante los Conversores de Analógico a Digital (ADC, por su nombre en inglés), «circuitos que, a una determinada frecuencia, toman 'fotografías' del sonido, que convierten en números que después son almacenados en el ordenador». Para poder escuchar esta onda digitalizada se debe recurrir a un proceso inverso, esto es, a la conversión de digital a analógica, que convierte los números almacenados en una señal eléctrica que posteriormente es filtrada. ${ }^{18}$

\section{CRITERIOS DE PROTECCIÓN}

Existen diversos criterios al momento de determinar si una obra es susceptible de ser protegida por el derecho de autor. Aspectos como el valor cultural o artístico de la obra (que dice relación con una cuestión de gustos), el destino de la obra (el fin con el que fue creada) o su forma de expresión (escrita u oral, por ejemplo), han sido desestimados por la doctrina al momento de determinar cuándo una obra estará protegida por el derecho de autor (Lipszyc, 2005: 67-68). En el tema que nos compete en este artículo, son dos los principales criterios que suelen tenerse en consideración: la doctrina del sweat of the brow y la doctrina de la originalidad. Cada uno persigue fines distintos, protegiendo en el primer

I7. U. Zscherpel, «Film digitization systems for DIR: Standards, Requirements, Archiving and Printing», NDT.net, disponible en <http://www.ndt.net/article/vo 5 no 5/zscherp/ zscherp.htm>.

I8. «Digitalización del sonido», disponible en <http://boj.pntic.mec.es/jgomez46/documentos/cav/sonidodigital.pdf>. 
caso el esfuerzo y trabajo invertido, y en el segundo caso la creatividad expresada (Clayton Newell, 2010: I6).

\section{SWEAT OF THE BROW}

La doctrina del sweat of the brow (literalmente «sudor de la frente») sostiene que la protección de una determinada obra a través del derecho de autor dependerá del trabajo que haya tomado su creación. Lo que se premia, en este caso, sería el esfuerzo invertido en la realización de la obra (Dobson, 2009: 323). Esta doctrina surgió en el Reino Unido, y a partir de ahí se extendió a países del common law como Australia y Nueva Zelanda. El primer caso británico que utilizó el criterio fue Walter $v$. Lane, en el que un reportero alegaba tener derechos de autor sobre las transcripciones que él realizó de unos discursos. El tribunal, tomando en cuenta el esfuerzo llevado a cabo por el reportero, acogió su pretensión y reconoció que las transcripciones que hizo estaban protegidas y no podían ser utilizadas sin su permiso (Hariani y Hariani, 20 I I: 497-498).

Se ha dicho que la adopción del criterio del sweat of the brow se debe a un cambio de paradigma en la economía, relacionado específicamente con la idea que se tiene del concepto de autor:

El paradigma del autor individual tratando de crear una obra original, en muchos contextos, ha sido sustituido por una inversión de capital y mano de obra para producir obras que reflejen un esfuerzo rutinario colectivo para generar una compilación para un mercado comercial. A medida que la importancia del autor individual disminuye, la necesidad de vincular el monopolio de los derechos de autor al autor sustituto — capital y mano de obra— aumenta (Scassa, 2006: 257).

El sweat of the brow se ha usado como argumento principalmente en los debates relativos a la protección de compilaciones y bases de datos, que si bien no siempre cumplen el requisito de la originalidad, requieren de esfuerzo y trabajo para su creación. Los defensores de este criterio han dicho que la obtención y organización de datos exige dedicación y recursos, por lo que no sería justo que el resultado fuese utilizado por otras personas. Si terceros quieren utilizar esos datos, entonces deberán reunirlos y recopilarlos por su cuenta. No obstante, también se ha empleado para argumentar la protección de reproducciones de obras 
preexistentes, debido a que requieren de dedicación y un determinado procedimiento (Cameron, 2006: 4I). Claramente, no requiere la misma dedicación fotocopiar o escanear un dibujo que fotografiar una pintura. Se ha dicho, además, que simplemente porque un proceso es laborioso y requiere habilidad técnica no lo hace poco original o poco creativo. Robin J. Allan ha sostenido que «una compilación predecible de números de teléfono en orden alfabético según los apellidos no requiere la misma creatividad que la fotografía artística, donde las decisiones de iluminación y lentes producen un resultado diferente» (Allan, 2007: 976-977).

Sin embargo, el criterio en cuestión no está exento de críticas. Algunos autores han señalado que no basta con una dedicación o esfuerzo superior al promedio, sino que se requiere emplear algo más. Así, la jurisprudencia estadounidense ha señalado que el autor debe haber creado la obra «con su propia habilidad, trabajo y juicio, sin copiar directamente o imitar evasivamente el trabajo de otro». Se ha dicho, además, que el requisito exigido corresponde a una habilidad artística verdadera (true artistic skill), y no a una mera habilidad de artesano (skill of an artisan). ${ }^{19}$

El sweat of the brow despierta ciertas dudas. Su principal problema es la falta de certeza, ya que no entrega elementos claros para determinar cuándo una obra será merecedora de protección. Esto obligará a que sean los jueces, a fin de cuentas, quienes deban dilucidar el tema (Colombet, I997: I 5). Lo que para alguien puede significar una labor que requiere gran dedicación y conocimientos, puede ser para otra una tarea simple o mecánica. Sin ir más lejos, y tomando en cuenta el tema de la presente monografía, existen diversas formas de digitalizar una obra, como en el caso de los libros. Los libros o documentos pueden ser digitalizados ya sea a través de su escaneo o a través de su transcripción. ¿Son ambos resultados protegibles por el derecho de autor o habría que ver en cuál se invirtió más esfuerzo?

Otro de los problemas de la teoría es que al proteger el esfuerzo dedicado en la confección de la obra, y no la originalidad de su expresión, se llegaría incluso a una especie de protección de los hechos. En Canadá, país que recogía este criterio al momento de determinar si una obra estaba protegida o no por el derecho de autor, se señaló que era posible pro-

19. Citando el caso Alva Studios, Inc. v. Winninger (Matz, 2000: 8). 
teger mapas, que están hechos a partir de información fáctica, como la geografía de un lugar determinado o las carreteras y caminos existentes.

En la causa Weetman v. Baldwin un tribunal canadiense concluyó que el esfuerzo y dedicación invertidos al momento de registrar las rutas existentes en una montaña eran suficientes para proteger el mapa en el que fueron indicadas. Lo que se pretende con este tipo de protección es que los terceros que quieran utilizar tal información estén limitados a dos opciones: recolectar la información por sí mismos o pagarle a quien la haya recolectado primero (Scassa, 2006: 26I-263). En Estados Unidos se han rechazado estos intentos por monopolizar información fáctica a través del derecho de autor, optando por determinar su protección examinando la originalidad de la forma en que está expresada tal información. Así, en el caso Miller v. Universal City Studios Inc. se sostuvo:

La línea trazada entre los hechos no protegibles por el derecho de autor y la expresión protegible de los hechos tiene un rol fundamental en el derecho de autor. Proporciona un medio de equilibrar el interés del público en la estimulación de la actividad creativa [...] en contra de la necesidad del público de tener acceso sin restricciones a la información. Permite que un autor posterior aproveche y añada a los logros anteriores sin duplicar innecesariamente su esfuerzo. ${ }^{20}$

Algunos autores han señalado que si bien el criterio del sweat of the brow es útil, no es suficiente para poder determinar si una obra es protegible o no (Cameron, 2006: 54). Se ha dicho que «la 'habilidad' de la pieza no puede ser aislada como un elemento protegible, y un trabajo protegido únicamente por su habilidad carecería de nuevas distinciones identificables y protegibles». De lo contrario se permitiría la protección de reproducciones exactas de obras preexistentes, lo que no generaría un beneficio nuevo para la sociedad (Butler, I998: 92-93). Se requiere, por lo tanto, un elemento distinto, que sirva como pilar central para determinar la protección de una obra; las dificultades que genera el criterio llevaron en I99 I a la Corte Suprema de Estados Unidos ${ }^{21}$ a concluir que

20. Corte de Apelaciones del Quinto Circuito (I98I), Miller v. Universal City Studios, Inc., disponible en <http://www.law.cornell.edu/copyright/cases/650_F2d_I365.htm>.

2I. En el caso Feist Publications, Inc., v. Rural Telephone Service Co., 499 U.S. 340 (I99I). El fallo es analizado en la sección de jurisprudencia del presente artículo. 
el sweat of the brow no era lo suficientemente eficaz para determinar si una obra era o no protegible por el derecho de autor (Blanke, 2002: 656). No obstante, aún existen países que utilizan un criterio similar en ciertos casos. $^{22}$

\section{LA ORIGINALIDAD}

Un breve vistazo a la legislación sobre derecho de autor de cada país permite distinguir un elemento que se repite al momento de definir qué tipo de obras son protegidas por esta figura jurídica. Tal elemento es la originalidad en la expresión de la obra, que está presente en estas normas expresamente o a través de frases que apuntan a su esencia (Colombet, I997: I3-I4). Así, la Copyrigt Act de Estados Unidos establece que una obra podrá ser protegida a través del derecho de autor si consiste en una «obra original de autoría fijada en cualquier medio de expresión tangible». El requisito también está presente en las leyes de países como España, ${ }^{23}$ Austria, Nicaragua, Túnez y Marruecos (Colombet, I997: I3). Por su parte, la OMPI define la palabra obra como «toda creación intelectual, original, expresada en una forma reproducible». ${ }^{24}$ La Comunidad Andina, en su Decisión 35 I sobre derecho de autor y derechos conexos, definió obra como «toda creación intelectual original de naturaleza artística, científica o literaria, susceptible de ser divulgada o reproducida en cualquier forma». ${ }^{25}$ La originalidad es, por tanto, una idea de suma relevancia al momento de determinar cuál es el objeto de protección del derecho de autor.

22. En I996, la Unión Europea reconoció en una de sus directivas un derecho sui generis que protege aquellas bases de datos que si bien no tienen una composición o selección original, sí son el producto de una inversión relevante en la obtención o presentación de sus elementos (Blanke, 2002: 675-676).

23. La Ley de Propiedad Intelectual de España señala que «son objeto de propiedad intelectual todas las creaciones originales literarias, artísticas o científicas expresadas por cualquier medio o soporte».

24. Citando el Glosario de la Organización Mundial de la Propiedad Intelectual, I 980, voz 262 (Vega Jaramillo, 2010: I6).

25. Comunidad Andina, Decisión 35 I: Régimen común sobre derecho de autor y derechos conexos, I993, disponible en <http://www.comunidadandina.org/normativa/dec/ D35r.htm>. 
Sin embargo, la originalidad no es un concepto fácil de definir, siendo muchas veces confundida con la idea de novedad, que es utilizada en materia de propiedad industrial. La doctrina francesa opta por separar ambos conceptos, señalando que la originalidad se caracteriza por una apreciación subjetiva, mientras que la novedad se mide objetivamente. De esta forma, Claude Colombet define a la originalidad como «la marca de la personalidad que resulta del esfuerzo creador», y a la novedad como «la ausencia de homólogo en el pasado»(Colombet, I997: I3). Por su parte, Ricardo Antequera Parilli señala que una obra original "por su forma de expresión, debe tener características propias como para distinguirla de cualquiera otra del mismo género", diferenciándola así de las meras copias de la creación de otros y de las obras que sólo requieren de técnica (Antequera Parilli, 2007: 5I). En relación a la diferencia entre las ideas de novedad y originalidad, dicho autor sostiene: «Mientras la novedad alude a contenidos (y por eso las invenciones son patentables en cuanto constituyan una solución técnica novedosa y no por la manera como se exterioricen), la originalidad apunta a formas de expresión o, en su caso, a selección o disposición de contenidos» (Antequera Parilli, 2007: 54-55). La novedad dice relación más bien con la aplicabilidad industrial de la obra en cuestión, es decir, se encuentra delimitada «sobre la base de una nota de objetividad y superación del estado técnico en un momento determinado» (Tactuk Retif, 2009: 40).

Un punto de partida al momento de analizar este elemento, antes de revisar las aproximaciones jurídicas al tema, es buscando cuál es su significado de uso general. Para esto se puede revisar el diccionario de la Real Academia Española de la Lengua, que recoge diversas acepciones. Una de ellas define «original» como «dicho de una obra científica, artística, literaria o de cualquier otro género: Que resulta de la inventiva de su autor». Otra definición sostiene que es un adjetivo «que tiene, en sí o en sus obras o comportamiento, carácter de novedad». La existencia de diversas acepciones al momento de definir originalidad no es algo exclusivo de los diccionarios. Los autores ligados al derecho de autor tampoco tienen una definición única al momento de tratar el tema, por lo que se pueden diferenciar dos corrientes dentro de la doctrina: la originalidad objetiva y la subjetiva (Real Márquez, 200I: 3 ). 


\section{Originalidad objetiva}

La originalidad objetiva se encuentra más ligada a la idea de novedad de la propiedad industrial. Lo anterior se debe a que este criterio es utilizado mayormente en el derecho anglosajón, donde la obra posee una mayor relevancia que la figura del autor, producto de una «vocación económica más que personalista» (Márquez Robledo, 2004: 99). Este tipo de originalidad está a su vez dividida en dos vertientes, denominadas 'novedad objetiva' y 'novedad subjetiva'. La novedad objetiva es aquella conformada por las creaciones humanas objetivamente nuevas, es decir: «requiere la aportación al patrimonio cultural de algo que con anterioridad a la misma no existía» (Real Márquez, 200I: 3). Por lo tanto, para determinar si una obra es objetivamente original será necesario no solamente examinar la obra en sí, sino que todo el resto de las obras existentes para saber si efectivamente es un nuevo aporte al patrimonio cultural. Dicha tarea, que de por sí parece extremadamente difícil, se torna prácticamente imposible al no existir en la actualidad registros obligatorios de las obras protegidas.

Dentro de este criterio no hay acuerdo respecto al grado de novedad exigible para la protección de una obra. Un sector de la doctrina exige una novedad absoluta, es decir, que la obra sea totalmente nueva, mientras que otro sector opta por una novedad relativa. El número de obras que será protegido dependerá de la elección que se haga sobre este punto (Real Márquez, 200ı: 3-4). Lipszyc, por ejemplo, señala que la originalidad no debe ser absoluta, ya que en el derecho de autor el término creación no significa «sacar algo de la nada». Según la autora: «no es necesario que la inspiración del autor esté libre de toda influencia ajena [...] El derecho de autor admite que la creación intelectual se realice sobre la base de elementos previos». Lo que exige, por ende, es que «la obra sea distinta de las que existían con anterioridad, que no sea una copia o imitación de otra» (Lipszyc, 2005: 66).

Aunque la novedad objetiva está generalmente ligada al sistema anglosajón, también ha sido reconocida por la jurisprudencia continental. El Tribunal Supremo de España sostuvo en una sentencia del año 2004:

Según autorizada doctrina científica, el presupuesto primordial para que la creación humana merezca la consideración de obra es que sea 
original, cuyo requisito, en su perspectiva objetiva, consiste en haber creado algo nuevo, que no existía anteriormente; es decir, la creación que aporta y constituye una novedad objetiva frente a cualquier otra preexistente (Antequera Parilli, 2007: 52).

La novedad objetiva, sobre todo en su vertiente absoluta, ha sido criticada ya que consiste en un criterio muy parecido al requisito de novedad utilizado en materia de propiedad industrial. Tal similitud es cuestionable si se toman en cuenta los objetivos que ambas instituciones persiguen. En materia de patentes lo que se busca es proteger «la innovación tecnológica y, normalmente, cada nueva patente desbanca una anterior que tecnológicamente ya se ha quedado anticuada"; mientras que en el derecho de autor se protegen «las aportaciones individuales al patrimonio cultural de la nación sin que las nuevas aportaciones devalúen las anteriores» (Real Márquez, 200I: 4).

La novedad subjetiva, por su parte, sostiene que una obra será original «en la medida en que sea fruto de la creación de su autor, a pesar de que existiera otra obra igual, siempre y cuando éste no haya querido copiar la existente ni consciente ni inconscientemente» (Real Márquez, 200I: 4). Uno de los problemas de esta doctrina es que permitiría la protección de obras iguales, mientras tengan distinto titular. Además, ante la existencia de dos o más obras que posean un alto grado de similitud, se deberá probar que no hubo deseos de copiar a la preexistente (Real Márquez, 200I: 5). Se genera, por lo tanto, un problema de tipo procesal, al establecer un nivel probatorio mayor en contra de la parte demanda, que deberá acreditar que las similitudes entre su obra y la del demandante son producto de una coincidencia, y no fueron premeditadas.

\section{Originalidad subjetiva}

Una creación tendrá originalidad subjetiva cuando sea «el reflejo de la personalidad de su autor» (Real Márquez, 200I: 5). Es decir, debe tener características propias que permitan distinguirla a grandes rasgos de otras obras del mismo género (Antequera Parilli, 2007: 5 I). Esta concepción de originalidad está más ligada a las ideas de singularidad o individualidad que a la de novedad. La razón es que la originalidad subjetiva es utilizada principalmente en el derecho de autor de corriente civil, en 
el que se le otorga una mayor relevancia a la figura del autor frente a la obra (Márquez Robledo, 2004: 96). Un fallo del Tribunal de Defensa de la Competencia y de la Propiedad Intelectual de Perú permite identificar más claramente las características básicas de este criterio de protección:

Debe entenderse por originalidad de la obra la expresión (o forma representativa) creativa e individualizada de la obra, por mínimas que sean esa creación y esa individualidad. La obra debe expresar lo propio del autor, llevar la impronta de su personalidad.

No será considerado individual lo que ya forma parte del patrimonio cultural artístico, científico o literario, ni la forma de expresión que se deriva de la naturaleza de las cosas ni de una mera aplicación mecánica de lo dispuesto en algunas normas jurídicas, así como tampoco lo será la forma de expresión que se reduce a una simple técnica o a instrucciones simples que sólo requieren de la habilidad manual para su ejecución.

En consecuencia, no todo lo producido con el esfuerzo de su creador merece protección por derechos de autor. ${ }^{26}$

Esta postura ha sido criticada por ciertos autores, ya que permitiría la protección de obras que son simplemente copias de otras, debiendo cumplir solamente el requisito de reflejar la personalidad de su autor. La crítica en cuestión puede ser rebatida señalando que no todas las creaciones humanas reflejan la personalidad de sus autores, por lo que no toda copia de una obra preexistente será protegida a través de este criterio. Además, en el caso de que la "copia» refleje efectivamente la personalidad del autor que la creó, estaríamos frente a una nueva obra que goza de individualidad debido a ese reflejo, por lo que no habría problema alguno en protegerla a través del derecho de autor (Real Márquez, 200I: 5). Distinto es el caso de, por ejemplo, «copias serviles» que se limitan a reproducir una obra preexistente con la mayor fidelidad posible.

Por otro lado, no es del todo claro cuándo se cumpliría con el requisito exigido por el criterio de la originalidad subjetiva, ya que un sector de la doctrina sostiene que toda creación humana es protegible, dado que refleja la personalidad de su autor, y otro sector sostiene que

26. Indecopi, Resolución 286-I998-TPI-Indecopi, disponible en <http://www.indecopi.gob.pe/repositorioaps/o/o/jer/-I/Resoluciono286-98-TPI.pdf>. 
el criterio en cuestión restringiría el actual espectro de obras protegidas. Se ha respondido a este cuestionamiento señalando que «una cosa es determinar quién ha sido el creador de un objeto y otra cosa pronunciarse sobre la originalidad del mismo, es decir, la ausencia o desconocimiento del autor no condiciona la originalidad de la creación» (Real Márquez, 200I: 6).

Respecto al segundo punto, relativo a que la originalidad subjetiva restringiría el actual espectro de obras protegidas, se ha dicho que ciertos tipos de obras no reflejan claramente la personalidad de su creador, por lo que no podrían estar protegidas por el derecho de autor. Un ejemplo de éstas son las bases de datos y el software, que responden «más a aplicaciones técnicas de algoritmos matemáticos o a un orden sistematizado indicado por la lógica» (Márquez Robledo, 2004: 97). Sin embargo, esta crítica ha sido respondida señalando que en el caso de las obras citadas sí existe un reflejo de la personalidad del autor o autores, aunque es más difícil de percibir que en el caso de las pinturas o las esculturas. Así, «los desarrolladores de software escriben los programas dependiendo de una cantidad de variables (fin del programa, plataforma en la que corre, etcétera) y una de ellas es su personalidad. Este reflejo puede ser el código fuente o incluso tan sólo los colores que se ven en la pantalla» (Márquez Robledo, 2004: 98). Además, la originalidad subjetiva no debe ser confundida con el mérito o valor artístico de la obra: «El juez deberá verificar si la obra contiene la impronta de la personalidad del autor, con lo cual quedará satisfecho el requisito de originalidad, sin que el valor que se le atribuya a la obra pueda actuar como condicionante de la protección» (Lipszyc, 2005: 67).

La noción de originalidad subjetiva puede relacionarse con la distinción que hace el derecho de autor respecto de las ideas y las formas de expresión de éstas. Como se ha reconocido en diversos tratados internacionales y leyes de países a lo largo del mundo, lo que el derecho de autor protege es la expresión de las ideas y no las ideas en sí mismas. En otras palabras, sólo se protege «al ropaje con que las ideas se visten» (Antequera Parilli, 2007: 45). Es posible, por lo tanto, que dos o más autores se basen en la misma idea logrando obras distintas entre sí, ya que la personalidad de cada autor la interpretará y expresará de diversa forma. Esto se puede observar en el arte religioso y, específicamente, en el cristiano, que ha producido diversas obras a pesar de tener un número 
limitado de temas. ${ }^{27}$ Que las obras resultantes estén protegidas por el derecho de autor no impide que la idea pueda ser luego utilizada por otros autores, ya que es sólo la forma en que fue expresada lo que se protegió. Según palabras de David Nimmer:

El derecho de autor sobre un caniche de peluche [...] no puede impedir que cualquier otra persona comercialice su propio caniche; el dibujo de un pajar no concede ningún derecho que prevenga que otros dibujen el mismo pajar; y una fotografía de Oscar Wilde no impide que otros tomen una fotografía distinta del célebre dramaturgo (Nimmer, 200I: 2I).

La diferenciación ya señalada no se limita simplemente a las ideas, sino también a la utilización de elementos que se encuentren en una obra ajena, siempre y cuando tales elementos sean tomados de forma aislada. Sólo existiría infracción del derecho de autor cuando se tome «el conjunto de los elementos que reflejan la individualidad de la obra» (Lipszyc, 2005: 63). Como señala Ricardo Antequera Parilli al referirse a un razonamiento de un tribunal del estado de Nueva York:

Si bien en abstracto no son protegibles ni las rampas, ni las figuras de los carpinteros, gorilas o heroínas, sí son objeto de protección frente a la apropiación de terceros la particular expresión de Donkey Kong, el malvado gorila y la de un heroico carpintero que debe esquivar varios obstáculos mientras ascendiendo por escaleras, recoge premios para rescatar a una chica pelirroja, retenida por el gorila (Antequera Parilli, 2007: 49).

El resultado de esta concepción es en ocasiones «altamente enriquecedor, en otras trivial, pero lo que permite que cada generación impulse el lento avance de la civilización es la posibilidad de trabajar sobre lo existente, de proseguir el camino sin tener que rehacerlo» (Lipszyc, 2005: 62). La distinción entre idea y forma de expresión sería más difusa

27. Temas como «la crucifixión», «el bautismo de Cristo», «la asunción de la Virgen» o «las bodas de Caná» han sido interpretados por numerosos artistas, quienes han producido obras que, a pesar de estar basadas en la misma idea, pueden ser diferenciadas entre sí. Un ejemplo es lo que ocurre con «la última cena», que si bien tiene su representación más conocida en un mural de Leonardo da Vinci, también ha sido objeto de pintores como Duccio di Buoninsegna, Peter Paul Rubens y Salvador Dalí. 
en el caso de adoptar un criterio como el de la novedad de la propiedad industrial. Dado que en tal caso sólo se protegerían las obras que fuesen distintas a las ya existentes, sería difícil proteger aquellas obras que tienen ciertas similitudes entre sí. La originalidad subjetiva, unida a la diferenciación entre ideas y formas de expresión, previene que tal monopolio sea posible.

\section{Criterio intermedio}

Ante la ambigüedad de la jurisprudencia al momento de optar por la originalidad objetiva o la subjetiva, parte de la doctrina española ha optado por crear un criterio intermedio, que engloba elementos de ambas posiciones. Se ha señalado que determinar si una obra está protegida en virtud del criterio de la originalidad objetiva es inviable, ya que exige comparar la obra con todo lo existente en el patrimonio cultural anteriormente, mientras que la delimitación de la originalidad subjetiva como reflejo de la personalidad «nos obligaría a un estudio detallado por parte de expertos en la materia para otorgar protección a cualquier obra». Dado que, por separado, ambos criterios no resultan prácticos, algunos autores españoles decidieron unirlos, ya que no son incompatibles entre sí (Real Márquez, 200I: 9).

El criterio intermedio, aunque combina ambas posiciones, toma como base la originalidad subjetiva, estableciendo como requisito adicional a ésta la necesidad de una cierta "altura creativa», similar al de la originalidad objetiva. Es decir, se refuerza el criterio de la originalidad subjetiva con la exigencia de no copiar obras pertenecientes al patrimonio cultural ya existente (Real Márquez, 200I: 9-IO).

$$
* * *
$$

Explicadas las tres doctrinas señaladas, y sin importar cuál se adopte, todas permiten concluir que la copia fidedigna que se haga de una obra preexistente no podrá ser protegida por el derecho de autor. El requisito de la originalidad no lo permitiría. La única posibilidad de protección podría venir de la mano de la originalidad subjetiva, siempre y cuando la reproducción o copia refleje la personalidad del autor. Pero en dicho caso la impronta personal del autor evitaría que la creación fuese una 
mera copia de la obra preexistente, ya que contendría elementos que la convertirían en una obra distinta, individualizable de la anterior. Es preciso aclarar que la originalidad es una cuestión de hecho, por lo que deberá ser apreciada atendiendo a cada caso en particular. Es difícil establecer un criterio general que abarque a todos los tipos de obras.

\section{PROTECCIÓN DE LA FOTOGRAFÍA}

La protección de las fotografías requiere una explicación separada, ya que la naturaleza de esta actividad varía, a lo menos superficialmente, de disciplinas como la pintura o la escritura. La creación de la fotografía levantó dudas al momento de determinar si formaba parte de las obras que son protegidas por el derecho de autor, sobre todo por su carácter mecánico (Cameron, 2006: 38). Antes de la fotografía, el derecho de autor se debió relacionar con artes «manuales» (que requerían la utilización de cinceles y brochas) y «abstractas» (la escritura), por lo que la nueva naturaleza que implicaba la fotografía era difícil de comprender (Hughes, 20I I: 6). Además, tal disciplina tiene como característica principal su fidelidad al momento de registrar algo. Cuando se fotografía, por ejemplo, un jarrón, el resultado será una imagen lo más parecida posible al jarrón. ${ }^{28}$ ¿Cómo, entonces, se puede cumplir el requisito de originalidad en este tipo de obras? Se ha entendido que la originalidad de la obra dependerá de las decisiones que tome el fotógrafo acerca de elementos como la luz, la ubicación de la cámara o el ángulo desde el cual se toma la fotografía (Dobson, 2009: 325-326). Son estas decisiones las que le otorgarán originalidad a la fotografía, debido a que constituye un ejercicio intelectual que variará dependiendo de cada fotógrafo. ${ }^{29}$

En relación a la ley británica, se ha sostenido que las fotografías pueden cumplir el requisito de originalidad en tres casos. El primero depende de cómo es registrada la fotografía, siendo relevantes la iluminación, filtros, ángulos, exposición y efectos en general. No será lo mismo tomar

28. Una de estas críticas, como se señala en el caso SHL Imaging, Inc. v. Artisan House, Inc. de la jurisprudencia estadounidense, es que la fotografía «copia todo pero no explica nada, es ciega en la esfera del espíritu».

29. En el caso Burrow-Giles Lithographic Co. v. Sarony, I I I U.S. 53 ( I 884), que será analizado más adelante, se definieron los criterios de protección de las fotografías. 
la fotografía de una estatua de frente que de costado. El segundo caso dice relación con la oportunidad (timing), es decir, con el momento elegido para capturar la escena en cuestión. Por ejemplo, dos fotografías de un caballo galopando serán distintas entre sí según el instante en que se hayan tomado. Y finalmente, el tercer caso tiene relación con la creación de la escena registrada, como cuando se determina su composición (Dobson, 2009: 344-345). La doctrina estadounidense ha establecido criterios similares, sosteniendo que los tres aspectos en virtud de los cuales una fotografía puede ser original son: elementos que no dependen de la creación de la escena (como el uso de la luz, filtros, lentes, exposición), elementos que dicen relación con la composición de la escena (la pose o ubicación de los elementos a fotografiar), y, por último, la oportunidad (timing) (Atkinson-Bonasio, 20II: 3).

Respecto a la elección de filtros o lentes al momento de tomar una fotografía, se ha señalado que no son estas decisiones por sí solas las que le otorgan la originalidad necesaria a la obra para estar protegida por el derecho de autor. Lo que es relevante es el resultado que se logra con tales decisiones (Hughes, 20I I: 36). Para ejemplificar esto de forma más clara, se puede decir que «la originalidad de un guión no puede depender de la elección del procesador de texto» (Hughes, 20II: 37). Basar la protección de una fotografía exclusivamente en la utilización de determinado equipamiento o incluso en la dedicación invertida por el autor está más ligado a un criterio como el del sweat of the brow que al de la originalidad.

Si bien la fotografía es un tipo de obra que está protegida por el derecho de autor, autores estadounidenses han señalado que éstas carecerían de originalidad y, por lo tanto, no cumplirían con tal requisito exigido para la protección en dos casos. El primero de ellos corresponde a la fotografía de una fotografía u otra obra impresa, donde el resultado no es más que una copia servil (slavish copy) del objeto fotografiado. El segundo caso tiene lugar cuando un fotógrafo imita las decisiones tomadas por otro en relación a la iluminación, objeto, ángulos u otros, para lograr el resultado creado en una fotografía preexistente (Dobson, 2009: 325-326).

La protección de una fotografía va a depender en gran parte de la naturaleza del objeto registrado, debiendo diferenciar entre aquellos que son bidimensionales y los que son tridimensionales (Butler, I998: I07). 
Al fotografiar un objeto tridimensional, como una escultura, el fotógrafo deberá determinar aspectos como la iluminación, el ángulo o el lente a utilizar, lo que dependerá de la visión de cada fotógrafo. Según la decisión que adopte, la fotografía resultante será distinta. La fotografía de un objeto bidimensional, en tanto, no variará en aquellos casos donde lo que se pretende es reproducir dicho objeto lo más fielmente posible. No obstante, es necesario aclarar que esta diferenciación ha sido criticada por los partidarios del criterio del sweat of the brow, quienes han señalado que «una fotografía no puede duplicar de forma precisa una escultura; la fotografía sólo captura una porción de la obra. Pero el mismo argumento puede hacerse respecto de la fotografía del detalle de una obra bidimensional» (Allan, 2007: 978).

\section{REPRODUCCIONES Y OBRAS DERIVADAS}

Al hablar de la originalidad como elemento de las obras protegidas por el derecho de autor, es necesario además referirse a la distinción entre las reproducciones y las obras derivadas. Ambas constituyen los productos de dos derechos, el de reproducción y el de variación, adaptación o transformación, que son reconocidos por tratados internacionales y la legislación interna de los países como algunos de los derechos patrimoniales exclusivos que posee un autor sobre su obra protegida..$^{30}$ Dado que este artículo se centra en el dominio público, no se entrará en mayores detalles respecto de tales derechos, ya que se entiende que el uso de tales obras ya no está sujeto a la voluntad del autor, sino que cualquier persona es libre de utilizarlas como le plazca. Lo que se analizará a continuación son los productos que surgen de estos derechos y su eventual protección.

La razón del siguiente examen es que la digitalización de una determinada obra requiere la existencia de una obra base, es decir, el objeto que será digitalizado. Las versiones digitales de obras en el dominio público no consisten en obras originarias o creadas desde cero, sino que requie-

30. El Convenio de Berna reconoce el derecho de reproducción en su artículo 9 y el de transformación en el I2. En el caso de Chile, las letras c) y d) del artículo i 8 de la Ley de Propiedad Intelectual reconocen los derechos de reproducción y transformación, respectivamente. 
ren la existencia de la obra que fue digitalizada (la pintura, el libro, el documento, la escultura). Por lo tanto, es necesario determinar si tales versiones digitalizadas corresponden a una reproducción o a una obra derivada, lo que influirá también en la protección que recibirán. Si la transformación de una determinada obra no es lo suficientemente relevante para dar lugar a una obra derivada, entonces estamos ante una reproducción (Tactuk Retif, 2009: I23).

\section{REPRODUCCIÓN}

La reproducción, según nuestra Ley de Propiedad Intelectual, es «la fijación de la obra en un medio que permita su comunicación y la obtención de copias de toda o parte de ella, por cualquier medio o procedimiento». ${ }^{3}$ La OMPI establece una definición similar, pero más completa, al señalar que el derecho de reproducción consiste en «una [nueva] fijación de una obra [...] suficientemente estable como para que pueda ser percibida, reproducida y comunicada [de nuevo]» (Ficsor, 2003: 320). Estas definiciones difieren del sentido general de la palabra reproducción, que la limita a la idea de copiar o multiplicar un determinado objeto. Como señala Antequera Parilli, la reproducción — vista desde la óptica del derecho de autor- engloba tanto la idea de obtener varios ejemplares como la de fijar la obra en un determinado soporte (Antequera Parilli, 2007: IOI). Así, serán reproducciones de un discurso tanto su grabación en una cinta de audio como la transcripción literal que se haga de él.

Los modos de reproducción son múltiples, incluyendo el dibujo, el grabado, la fotocopia, el moldeado, la impresión, la microfilmación y básicamente cualquier procedimiento «que permita comunicar la obra de una manera indirecta, es decir, a través de una copia de la obra en la que se corporiza la reproducción» (Lipszyc, 2005: I 80). Si bien algunas definiciones del derecho de reproducción sólo mencionan la fijación material de la obra, se entiende que se puede ampliar hasta incluir a la inmaterial, como en el caso de las digitalizaciones (Jadue Becker, 2004: 57). Lo anterior tiene relación con el carácter simplemente enunciativo de las modalidades a través de las cuales se puede realizar una reproducción (Antequera Parilli, 2007: I02). La idea fue reconocida por el Tratado de

3I. Ley I7.336, artículo 5 letra u). 
la OMPI sobre Derecho de Autor, al aclarar en una declaración concertada que las reglas relativas al derecho de reproducción establecido en el Convenio de Berna «son totalmente aplicables en el entorno digital, en particular a la utilización de obras en forma digital. Queda entendido que el almacenamiento en forma digital en un soporte electrónico de una obra protegida constituye una reproducción en el sentido del artículo 9 del Convenio de Berna».32

La reproducción de obras plásticas ha dado origen a diversas opiniones. Existen autores que sostienen que es imposible reproducir este tipo de obras ya que el resultado nunca será el mismo al original: «una obra plástica singular tiene sus propias características, y el cambio del soporte de la obra plástica da lugar a una imagen de la obra que no se corresponde con la misma, por lo que se tratará de una obra derivada, es decir, que incorpora elementos de la obra anterior de la que parte». Otra postura, menos extrema, sostiene que si bien la ejecución manual no puede ser considerada una reproducción de este tipo de obras, sí acepta la reproducción a través de medios como la grabación audiovisual o la fotografía (Ribera Blanes, 2002: I 86). La exclusión de la reproducción manual de obras plásticas deriva, según estos autores, de la falta de identidad entre el original y la copia y de la «habilidad técnica necesaria para la realización de la copia que hace que esa actividad esté más cercana a la elaboración que a la reproducción, ya que el que copia siempre deja la impronta de su personalidad» (Ribera, 2002: I 87). Sin embargo, se ha criticado esta postura al señalar que la falta de identidad no se condice con la existencia de falsificaciones casi perfectas de obras de artistas famosos (Ribera, 2002: I 88). El argumento de la falta de identidad ha sido también atacado con la figura de la «reproducción representativa», que no exige una identidad absoluta entre la copia y la obra original:

Para que haya reproducción no es necesario que el ejemplar obtenido sea completamente idéntico, en cuanto al color o la dimensión, al original, ni que se obtenga a través del mismo procedimiento, sino que es suficiente que el resultado en el que la reproducción se sustenta sea tal que se desarrolle tanto una función vicaria como una función simplemente representativa respecto al original, de forma que cualquier

32. Declaración concertada respecto del artículo I.4, Tratado de la OMPI sobre Derecho de Autor. 
individuo pueda hacerse una composición mental de la obra intelectual, tal y como fue ideada y ejecutada por el autor (Ribera, 2002: I9I).

En relación a las reproducciones realizadas a través de la fotografía o la grabación audiovisual, la respuesta a los autores que las excluyen como formas de reproducción es similar a la anteriormente citada. Se ha dicho que la utilización de un soporte distinto al de la obra original no es suficiente para sostener que estamos ante una nueva obra, ante una obra derivada. Además, dado que ni los tratados internacionales ni las leyes internas exigen que la reproducción sea realizada en el mismo soporte de la obra original, no corresponde hacer una distinción de este tipo (Ribera, 2002: I92-I93).

La profesora Begoña Ribera ha sostenido que para poder determinar cuándo estamos ante una reproducción es necesario examinar dos aspectos, el resultado obtenido y el ánimo o voluntad del sujeto que reproduce. Ribera aclara que el elemento subjetivo, la voluntad de llevar a cabo una obra que reproduzca el original, no debe ser examinado por sí solo, sino que debe combinarse con el resultado obtenido. De esta forma, si el resultado es de tal calidad que las diferencias con el original son apenas perceptibles, entonces estaremos ante una reproducción. Por el contrario, si cualquier persona puede diferenciar el original de la copia, entonces se tratará de una transformación que dio origen a una obra diferente (Ribera, 2002: I94).

\section{OBRA DERIVADA}

Este tipo de obras surge a partir del ejercicio del derecho de transformación o adaptación sobre una obra preexistente. La ley chilena define a la obra derivada como «aquella que resulte de la adaptación, traducción u otra transformación de una obra originaria, siempre que constituya una creación autónoma». 33 Por su parte, la ley define obra originaria como "aquella que es primigénitamente creada».34 El glosario de la OMPI aclara que en el caso de la obra originaria «su originalidad es absolutamente de primera mano y no meramente complementaria, como sucede

33. Ley $17 \cdot 336$, artículo 5 letra i).

34. Ley I7.336, artículo 5 letra h). 
en el caso de obras derivadas de otras obras» (Herrera, I999: 56). Que su originalidad sea de primera mano no significa que no esté basada en algo, como en una idea o en un hecho, ya que éstos están fuera de la protección del derecho de autor. Por lo tanto, una novela que tiene como tema central la venganza, o que está basada en la caída del Imperio Romano, puede ser perfectamente una obra originaria según los términos ya señalados. Según Lipszyc, se consideran obras originarias aquellas que lo son «tanto en la composición como en la expresión». La composición consiste en el plan de desarrollo de la obra, mientras que la expresión dice relación con su forma (Lipszyc, 2005: 70).

La obra derivada, por lo tanto, es creada a partir de una obra preexistente, que sirve como base. Ejemplos de obras derivadas son las traducciones, que requieren la existencia de una obra originaria, que en dicho caso es el texto a traducir. La protección que se da a este tipo de obras deriva precisamente del requisito de originalidad, ya que son las variaciones que se le hacen a la obra base las que serán protegidas por el derecho de autor (Dobson, 2009: 326). Según lo señalado por la OMPI: «no puede significar cualquier transformación sino únicamente las que tienen como resultado nuevos elementos originales en relación con la forma inalterada de la obra» (Ficsor, 2003: 30). Además, tales variaciones deberán depender de la labor intelectual de su autor y no de meros cambios triviales (Butler, I998: 79). Es decir, se trata de «una actividad creadora que modifica o cambia parcialmente la identidad de la obra intelectual o artística inicial de manera que resulta una presentación en forma distinta de la originaria» (Tactuk Retif, 2009: I I 2). Es necesario aclarar que la obra derivada no debe ser una mera copia de la obra prexistente, ya que en tal caso sería una reproducción, ni debe estar solamente inspirada en la obra originaria, ya que en dicho caso el vínculo entre ambas sería más difuso, con lo cual la nueva obra sería una obra independiente, distinta de la obra previa.

La adaptación cinematográfica que se haga de una historia que se encuentra en el dominio público, como Blancanieves, puede ser protegida a través del derecho de autor, pero esta protección sólo abarcará aquellos elementos originales que los responsables de la adaptación hayan incorporado a la obra base. De esta forma, la historia no estará protegida por la creación de la adaptación, sino que permanecerá en el dominio público, y sólo los elementos adicionales, como el diseño de los personajes, 
las canciones y las variaciones en la trama, serán protegidos. Tal vez la versión cinematográfica más conocida de dicha historia sea la creada por Walt Disney en 1937, pero no es la única. El estudio Disney no puede impedir que otras personas adapten la historia de los hermanos Grimm, ya que su versión no afecta la (ausencia de) protección de la obra.

Esta diferencia entre obra originaria y elementos adicionales es relevante, ya que impide posibles monopolios sobre una obra que se encuentre en el dominio público. Permitir la protección total de la obra derivada entregaría una protección excesiva a la primera persona que realice la adaptación o transformación en cuestión, e impediría que otros realicen sus propias versiones. La solución actual, por lo tanto, impide este peligro y estimula la creatividad de los autores, animándolos a agregar nuevos elementos a los ya existentes. Para ejemplificar esto se puede citar la siguiente sentencia argentina:

Tratándose de la música de bailes populares que integra el patrimonio nacional y están en el dominio público, solamente puede pretenderse la exclusividad por quien acredite que su versión contiene elementos propios y una inspiración original, con caracteres suficientes para considerar que existe una creación personal distinta de la originaria, caso en que la protección se limita únicamente a dicho aspecto.

El transformador adquiere sólo la propiedad de la forma particular que haya dado al acompañamiento y la transformación que haya podido hacer. ${ }^{35}$

Sin embargo, la OMPI advierte que no todos los ejemplos enumerados por los tratados internacionales y las leyes nacionales constituyen obras derivadas. Respecto de las traducciones, el organismo sostiene que es necesario diferenciar:

En la 'recreación' de la obra en otro idioma deben encontrarse sus elementos originales - la misma estructura de los pensamientos, la misma expresión (sustantiva) de los sentimientos, la misma forma de presentación de la información, etcétera- en una nueva forma diferente. Y es en gran medida el texto original el que determina si hay espacio o no

35. Cámara Nacional de Apelaciones en lo Civil, Sala C (1978). Cresseri, A. Suc. vs. Sadaic. Disponible en <http://www.cerlalc.org/derechoenlinea/dar/index.php? mode= $\operatorname{archivo\& id}=167>$. 
para la creatividad. La traducción de una poesía, por ejemplo, requiere normalmente esfuerzos creativos, a menos que se haga una traducción aproximada (ofreciendo simplemente un vocabulario equivalente a las palabras del original). Por otra parte, un texto puramente técnico puede que no ofrezca la posibilidad de diversas opciones cuando se traduce con fidelidad; así pues, su traducción quizás no puede considerarse una creación intelectual y, por lo tanto, una obra (Ficsor, 2003: 29).

En el caso de reproducciones de obras en el dominio público, las instituciones que las crean sostienen que constituyen obras derivadas, distintas a las que sirven como base y, por lo tanto, protegibles a través del derecho de autor. Sin embargo, como ya se ha explicado, en el caso de las obras derivadas sólo son protegibles aquellos elementos que no están presentes en la obra subyacente (Matz, 2000: 4-6).

Al momento de reproducir una obra de arte, el objetivo principal es lograr la mayor fidelidad posible respecto a ella, parecerse lo más posible al trabajo que se está copiando. El mero cambio de medio, en este caso, desde la obra física a una versión digital, no satisface el requisito de la variación distinguible (distinguishable variation) (Matz, 2000: I3). Esto se debe a que cualquier conversión a un nuevo medio implicará la adopción de las características inherentes de dicho medio, como, por ejemplo, la fotografía de una pintura, que significa perder la textura que el lienzo y la pintura lograban. Estos cambios no dependen de decisiones artísticas de la persona a cargo de la reproducción, sino que son necesarios y triviales (Butler, I998: III-II3). Lo mismo ha sostenido la Copyright Office de Estados Unidos al señalar que «la versión digitalizada es una copia de la preexistente y estaría protegida como tal, pero no se crea una nueva obra de autor. Una novela puede ser digitalizada y almacenada en un medio electrónico. La protección depende de la situación de derechos de autor en la novela: la digitalización no añade ninguna autoría nueva [a la obra]» (U. S. Copyright Office, I998).

Se ha dicho también que dos fotografías de una misma obra de arte pueden variar entre sí dependiendo de las elecciones que haga el fotógrafo respecto de factores como la iluminación y los lentes que se ocupen en el proceso. La respuesta a este argumento ha señalado que tales diferencias no son relevantes, sino que simplemente triviales:

Considere una lista de números de teléfono y la Mona Lisa. Ambos 
están en el dominio público, el primero porque es una lista de datos, y la segunda porque está fuera del derecho de autor. Si hubiera que crear un directorio telefónico de la lista de números copiándolos en un libro, esa colección no caería bajo el derecho de autor a pesar de las ligeras decisiones estilísticas realizadas, como el tamaño de la letra y el número de nombres en cada página. Lo mismo ocurriría con la Mona Lisa. Si uno fuera a tomar una reproducción fotográfica de la pintura, las ligeras diferencias de estilo no deberían ser suficientes para permitir la protección de la nueva imagen. La información de la obra de arte original se encuentra esencialmente sin cambios en la preproducción. Si bien pueden haber diferencias minúsculas entre las reproducciones de dos fotógrafos, estas diferencias son del mismo tipo de las encontradas en dos guías telefónicas (Kelley, 20I I: 40).

Si se aplicara el criterio del sweat of the brow, y tales reproducciones fueran protegidas en su totalidad, el problema surgiría al momento de determinar qué es lo que se está protegiendo. Dado que no hay variaciones distinguibles entre la versión física de la obra y su símil digital, se podría llegar incluso al absurdo de proteger el mismo acto del cambio de medio, otorgando un monopolio a aquella persona que haya digitalizado primero la obra e impidiendo que otras personas lo hagan (Butler, I998: II3-II4).

\section{ANÁLISIS JURISPRUDENCIAL}

Para comprender de mejor manera las teorías explicadas, así como sus alcances, se procederá a examinar algunos casos jurisprudenciales. Debido al escaso desarrollo jurisprudencial del derecho de autor en Chile, los fallos examinados corresponden a sentencias emanadas de tribunales estadounidenses. La elección de estos se debe principalmente al relevante rol que han tenido estos tribunales al momento de definir los elementos básicos del derecho de autor.

En Burrow-Giles Lithographic Co. v. Sarony, la Corte Suprema de Estados Unidos estableció algunos criterios básicos en relación a la protección de las fotografías. La sentencia fue dictada en I 884, cuando aún no existía total claridad acerca de cómo esta nueva tecnología se relacionaba con el derecho de autor. De ahí la relevancia de la decisión del tribunal. La obra en cuestión era una fotografía del escritor Oscar Wilde, 
que fue tomada por Napoleon Sarony. La obra había sido posteriormente comercializada por una compañía litográfica llamada Burrow-Giles, la cual sostenía que la fotografía no estaba protegida por el derecho de autor, al no ser un «escrito» ni el fotógrafo era un «autor», según los términos utilizados por la Constitución de aquel país. En su sentencia, la Corte Suprema sostuvo que las fotografías sí formaban parte de las obras protegidas por el derecho estadounidense, ya que constituían una forma de expresión visible. ${ }^{36}$

Como segundo argumento, Burrow-Giles sostuvo que las fotografías eran meros procesos mecánicos y, por lo tanto, no alcanzaban la categoría de arte ni expresaban la idea de su autor, como sí ocurría en procesos como la pintura, el grabado y la impresión. Sin embargo, la Corte rechazó el argumento. Según el razonamiento del tribunal, la fotografía de Oscar Wilde sí cumplía con el requisito de ser una obra de arte original, ya que el fotógrafo se encargó de preparar la escena registrada indicándole al escritor que adoptara una pose determinada y vistiera cierto tipo de ropa, y preparó también la iluminación y la composición de la escena.

En L. Batlin \& Son, Inc. v. Snyder, dos compañías fabricaron alcancías del Tío Sam, basadas en un modelo que se encontraba en el dominio público. La original, que data de I 886 , estaba hecha de metal, mientras que la creada por la compañía llamada Snyder estaba hecha de plástico. La versión de Snyder no contenía mayores variaciones respecto del modelo de i 886, además del ya mencionado cambio de material y una leve reducción en el tamaño de la alcancía. Batlin demandó a Snyder ya que esta última había logrado que su alcancía fuese registrada como obra protegida por el derecho de autor. ${ }^{37}$

En 1976, el Segundo Circuito sostuvo que el derecho de autor de Snyder no era válido, dado que su alcancía no tenía una variación sustancial respecto del modelo que estaba en el dominio público. En la sentencia se señaló que «la mera reproducción de una obra de arte en un medio diferente no debería constituir la originalidad necesaria dado que nadie puede decir que ha evolucionado de forma independiente un me-

36. Corte Suprema de Estados Unidos, Burrow-Giles Lithographic Co. v. Sarony (I 884), disponible en <http://www.law.cornell.edu/supremecourt/text/I I I/53>.

37. Corte de Apelaciones del Segundo Circuito, L. Batlin \& Son, Inc v. Snyder (I976), disponible en <http://www.coolcopyright.com/cases/fulltext/batlinsnydertext.htm>. 
dio en particular». Los cambios, por tanto, debían ser sustanciales y no triviales. Permitir la protección de obras derivadas en base a cambios minúsculos «sólo serviría para poner un arma de hostigamiento en las manos de copiadores maliciosos que intenten apropiarse y monopolizar los trabajos que pertenecen al dominio público».

En Gracen v. Bradford Exchange se trata el tema de la protección de obras derivadas. La productora cinematográfica MGM contrató a la compañía Bradford Exchange para que diseñara una serie de platos coleccionables basados en personajes y escenas de la película El mago de $\mathrm{O} z$. Bradford organizó un concurso para que cualquier artista enviara una pintura de la actriz Judy Garland en el rol de Dorothy, con el objeto de escoger la mejor pintura y premiar al artista ganador con un contrato para diseñar toda la serie de platos coleccionables. La compañía facilitó fotografías de la actriz a los artistas para que pudieran crear sus pinturas. La ganadora del concurso fue una artista llamada Jorie Gracen, quien a pesar de haber sido premiada con el contrato lo rechazó ya que no estaba de acuerdo con algunas cláusulas. Debido a esto, el contrato fue firmado por otro artista, James Auckland..$^{8}$

Gracen demandó a Bradford Exchange sosteniendo que el plato que diseñó Auckland era una copia de la pintura que ella había creado. La Corte sostuvo que dado que MGM era el titular de los derechos de autor de la película El mago de $\mathrm{O} z$, la demandante no podía proteger su pintura. Pero además de tocar este tema, la sentencia trataba un aspecto que es más relevante para el presente trabajo, que es la originalidad de las pinturas de Gracen como obras derivadas. Para esclarecer este punto, el tribunal enunció un ejemplo que sirve como punto de partida:

Supongamos que un artista A realiza una reproducción de la Mona Lisa, una pintura en el dominio público, que difiere ligeramente de la original. B también hace una reproducción de la Mona Lisa. A, que ha protegido su obra derivada, demanda a B por infracción de sus derechos de autor. La defensa de B es que él estaba copiando la obra original, no la reproducción de A. Pero si la diferencia entre la original y la reproducción de $\mathrm{A}$ es leve, la diferencia entre las reproducciones de A y B también será leve, por lo que si B tuvo acceso a las reproducciones

38. Corte de Apelaciones del Séptimo Circuito, Gracen v. Bradford Exchange, I983, disponible en <http://openjurist.org/698/f2d/30o/gracen-v-bradford-exchange-m>. 
de A [...] será necesario decidir si B estaba copiando a A o a la Mona Lisa en sí. ${ }^{39}$

Según la sentencia, el mismo problema se presenta en el caso de Gracen. Los platos diseñados por Auckland son similares a las fotografías de la película y a la pintura de la demandante. El tribunal señala que Auckland declaró no haber visto la pintura de Gracen, pero en el caso de haberla visto sería muy difícil determinar si lo que él estaba copiando era la fotografía de la película o la pintura de la demandante. En una u otra hipótesis el resultado sería distinto, ya que en el primer caso él estaba autorizado por parte del titular de los derechos para copiar las fotografías. En la sentencia se aclara además que la protección de la obra de Gracen variaría según si hubiese pintado teniendo como modelo a la actriz Judy Garland o a las fotografías de la película, ya que «una obra derivada debe ser sustancialmente diferente de la obra subyacente para ser protegida por el derecho de autor»..$^{\circ}$

En Feist Publications, Inc. v. Rural Telephone Service Company, Inc., la compañía Feist Publications fue demandada por la copia de una guía de teléfonos creada por Rural. Uno de los pilares en el caso consistía en determinar si dicha guía de teléfonos era protegible o no a través de derecho de autor. En su sentencia de I99I, la Corte Suprema de Estados Unidos sostuvo que la originalidad era un requisito sine qua non del derecho de autor y, por lo tanto, para que un trabajo sea protegido debe haber sido "creado de forma independiente por el autor (a diferencia de copiado de otros trabajos), y poseer al menos un cierto grado mínimo de creatividad» (Matz, 2000: 5). Según la Corte, el hecho que Rural haya organizado los datos de la guía en orden alfabético no cumplía con este mínimo de originalidad exigido por la ley para la protección de una determinada obra. ${ }^{\mathrm{I}}$

El fallo en cuestión critica la doctrina del sweat of the brow, señalando que tal criterio permitiría la protección de una colección de datos sin tomar en cuenta las contribuciones originales que haya realizado el au-

39. Gracen v. Bradford Exchange.

40. Gracen v. Bradford Exchange.

4I. Corte Suprema de Estados Unidos, Feist Publications, Inc., v. Rural Telephone Service Co. (I99I), disponible en <http://caselaw.lp.findlaw.com/scripts/getcase. $\mathrm{pl}$ ? court $=\mathrm{US} \& \mathrm{vol}=499$ \&invol $=340>$. 
tor respecto de la selección y disposición de la información. Esto, según el tribunal, podría llegar incluso a proteger los meros datos y no la forma en que son expresados.

En Bridgeman Art Library, Ltd v. Corel Corp., la parte demandante es Bridgeman, una empresa británica que se dedicaba a la creación de réplicas fotográficas de obras de arte en el dominio público, para posteriormente vender licencias de uso sobre ellas. El demandado era Corel, una compañía canadiense que vendía productos de software, uno de los cuales consistía en unos CD-ROM que reunían cientos de reproducciones digitales de pinturas en el dominio público. Según Bridgeman, I 20 de esas reproducciones fueron sacadas de su propia colección, lo que constituía una infracción a los derechos que tenía sobre dichas imágenes (Matz, 2000: 9-IO).

El caso fue fallado dos veces, en noviembre de I 998 y marzo de 1999. En el primero, el tribunal utilizó la ley británica para determinar si las fotografías en cuestión estaban protegidas por el derecho de autor. Según la sentencia, el requisito de originalidad exigido por la ley británica no se cumple cuando el trabajo «está totalmente copiado de una obra existente, sin ninguna adición significativa, alteración, transformación o combinación con otro material» (Dobson, 2009: 330). Esto debido a que el objetivo de Bridgeman era duplicar de la forma más exacta posible las obras de arte que iban a reproducir.

Tras el primer fallo, Bridgeman presentó una moción señalando que el tribunal aplicó erróneamente la ley británica en relación al requisito de originalidad. Ante esto, el tribunal dictó una segunda sentencia, en la que aplicó la ley estadounidense en vez de la británica. La conclusión a la que llegó fue la misma que en el primer fallo, sosteniendo que:

el demandante ha reconocido que se ha esforzado por crear copias serviles (slavish copies) de obras de arte en el dominio público. Si bien puede suponerse que esto requiere habilidad y esfuerzo, no había chispa de originalidad; de hecho, el objetivo del ejercicio consistía en reproducir las obras subyacentes con absoluta fidelidad. Los derechos de autor no están disponibles en estas circunstancias (Dobson, 2009: 333).

En el caso en cuestión, el único elemento adicional que Bridgeman agregó a sus fotografías fue una tira de corrección de color que tenía por objeto asegurar que las reproducciones fueran «un reflejo genuino 
de la obra original». Por lo tanto, el único elemento protegible a través del derecho de autor era esa tira, y dado que las imágenes de Corel no la incluían, el tribunal rechazó la demanda de Bridgeman.42

En Meshwerks $v$. Toyota Motor Sales U.S.A. se trató el tema de las reproducciones de objetos tridimensionales. El demandante, una compañía llamada Meshwerks, alegaba que existió una infracción en los derechos de autor que tenía sobre la maqueta electrónica (wire-frame) de unos automóviles. Tales maquetas habían sido creadas para que la compañía Toyota realizara un comercial de televisión, pero su uso se extendió a proyectos adicionales. La parte demandada sostuvo que las maquetas carecían de la originalidad necesaria para la protección, señalando además que el titular de los derechos de autor era el diseñador de los vehículos y no quien creó las maquetas electrónicas. ${ }^{43}$

La digitalización se llevó a cabo recogiendo los datos de determinados puntos físicos del objeto a ser representado, que en el caso en cuestión eran vehículos marca Toyota. Tras cubrir los vehículos con una cuadrícula de cinta adhesiva, un brazo articulado recorrió los objetos y registró los datos en una computadora, los cuales fueron leídos por un software especial que generó las maquetas electrónicas respectivas. Sin embargo, estos modelos generados por el software no eran del todo fieles a los vehículos originales, por lo que empleados de Meshwerks debieron editarlos para que se asemejaran lo más posible a ellos. Según la parte demandante, el trabajo manual que realizaron sus trabajadores, que constituía aproximadamente el noventa por ciento del resultado, era fundamento suficiente para que las maquetas electrónicas estuvieran protegidas por el derecho de autor.

El tribunal de alzada, en su sentencia de 2008 , confirmó el criterio de la sentencia recurrida, sosteniendo que las maquetas electrónicas creadas por Meshwerks carecen de la originalidad necesaria para ser protegidas. En la sentencia se establece que el mero cambio de un medio a otro no es suficiente para ser considerada una variación significativa. En relación al

42. Tribunal de Distrito del Segundo Circuito, Bridgeman Art Library, Ltd v. Corel Corp. (I 998), disponible en <http://www.leagle.com/xmlResult.aspx? xmldoc $=1998446$ 25FSupp2d42I_I395.xml\&docbase=CSLWAR2-I986-2006>.

43. Corte de Apelaciones del Décimo Circuito, Meshwerks v. Toyota Motor Sales U.S.A. (2008), disponible en <http://caselaw.findlaw.com/us-Ioth-circuit/I 29I978.html>. 
trabajo que llevó crear las reproducciones digitales, los jueces señalaron que lo que se tomó en cuenta fue el producto final, y no el proceso de su creación, ya que el esfuerzo por sí solo no asegura la protección a través del derecho de autor. Según el tribunal:

Las maquetas electrónicas de Meshwerks muestran a los vehículos de Toyota sin ningún rasgo que los individualice: ellos se encuentran sin tocar por una brocha digital; no están representados frente a una palmera, zumbando por la carretera o subiendo la ladera de una montaña. Dicho de otra manera, los modelos de Meshwerks representan nada más que vehículos de Toyota sin adornos: el coche como el coche. ${ }^{44}$

$$
* * *
$$

El examen de los casos citados nos permite concluir que en Estados Unidos el requisito de la originalidad en la expresión es el principal criterio utilizado para garantizar la protección de una determinada obra. Sólo excepcionalmente se recurre al criterio del sweat of the brow, y cuando esto ocurre se combina con el ya mencionado requisito de la originalidad. Por lo tanto, no se toma en cuenta exclusivamente el trabajo y dedicación invertido por el autor en la creación de la obra para otorgarle protección sobre ella.

En las sentencias se señala que la protección de obras derivadas se basa en el criterio de la originalidad de la expresión, sosteniendo que en este tipo de obras sólo se protegen aquellos elementos nuevos que se agregaron a la obra originaria. Esto, ya que la protección de la obra derivada no puede afectar la protección que tenga la obra preexistente. También se aclara que el mero cambio de formato constituye una reproducción y no una transformación de la obra, por lo que el resultado no puede ser protegido a través del derecho de autor.

\section{EL CASO CHILENO}

En relación a aspectos estrictamente jurídicos, esto es, a si nuestro ordenamiento jurídico admite la protección de reproducciones de obras en el dominio público, la respuesta no es sencilla. En primer lugar, la

44. Meshwerks v. Toyota Motor Sales U.S.A. 
Ley de Propiedad Intelectual de Chile no menciona la originalidad como requisito esencial para la protección, señalando solamente que protege aquellas «obras de la inteligencia en los dominios literarios, artísticos y científicos, cualquiera sea su forma de expresión». La ausencia de la palabra «original» en la disposición citada puede llevar a concluir que en nuestro país sí es posible la protección de aquellas reproducciones que se limitan a copiar lo más fidedignamente posible alguna obra. La Convención de Berna tampoco hace referencia a este requisito (Jadue Becker, 2004: 72).

Aunque el requisito no sea mencionado en las normas legales, sí es recogido por algunos autores y organismos. Así, Claudio Ruiz Gallardo al enumerar los elementos característicos de la Ley de Propiedad Intelectual chilena, menciona a la originalidad: «No todas las obras que emanan del intelecto humano se encuentran protegidas, sino sólo las que suponen una creación con características nuevas y originales» (2008: 40). Paulina del Campo Almuna, en su memoria Evolución del derecho de autor en Chile, sostiene que uno de los requisitos para que una obra sea protegida por el derecho de autor es que sea original. Es decir, que sea «una expresión espiritual del esfuerzo humano, la cual tendrá que importar un trabajo innovador, que manifieste la personalidad del autor y no se limite a ser un reflejo servil de la actividad ajena» (Del Campo Almuna, 2003: I2). Cristian Schmitz Vaccaro también incluye a la originalidad como uno de los requisitos que deben cumplir las obras protegidas por el derecho de autor, sosteniendo que lo que diferencia a esta rama del derecho con la propiedad industrial es el tipo de originalidad requerida (objetiva o subjetiva), y no la originalidad en sí (2006: 40-43). Otro autor que se refiere a la originalidad como requisito de protección es Rodrigo Puchi Zurita, quien en un artículo sobre protección de programas de ordenador se refiere a las características que debe tener una obra para estar amparada por el derecho de autor (2006: I63). No obstante este reconocimiento por parte de algunos autores, un sector importante de la doctrina nacional no se refiere al tema de la originalidad como requisito para la protección de una obra, ni siquiera para rechazarla. Dina Herrera, por ejemplo, no trata el tema de la originalidad en su libro Propiedad intelectual, derechos de autor: Ley 17.336 y sus modificaciones, llegando a mencionarla sólo indirectamente al citar la definición que el glosario de la OMPI contiene sobre el término «obra literaria» (Herre- 
ra, I999: I 5). Tampoco lo hace Santiago Larraguibel, quien se limita a reproducir el texto de la Ley de Propiedad Intelectual al momento de referirse a su objeto de protección (Larraguibel, I979: 22-25).

El Departamento de Derechos Intelectuales de la Dirección de Bibliotecas, Archivos y Museos (Dibam), que tiene a su cargo el Registro de la Propiedad Intelectual en Chile, señala en su sitio web que las obras protegidas por la Ley de Propiedad Intelectual son aquellas «obras literarias y artísticas que tengan algún grado de originalidad».45 Esta exigencia deriva del reglamento de la Ley de Propiedad Intelectual, que establece:

[El conservador deberá inscribir] la propiedad intelectual de todo género de escritos, composiciones de música, pintura, dibujo, escultura, mapas y planos; proyectos de ingeniería y arquitectónicos, obras teatrales, cinematográficas, fotográficas, fonogramas, interpretaciones grabadas y emisiones y, en general, de toda obra científica, literaria o artística que tenga valor de creación original. ${ }^{46}$

Si bien las normas legales chilenas no mencionan expresamente a la originalidad como un requisito para la protección de las obras a través del derecho de autor, sí señalan algunas exigencias que no pueden obviarse. Ya en su Código Civil, Andrés Bello reconocía que las «producciones del talento o del ingenio son una propiedad de sus autores».47 Por su parte, la Constitución Política de la República establece que los autores gozarán de ciertos derechos sobre «sus creaciones intelectuales y artísticas de cualquier especie, por el tiempo que señale la ley».48 $\mathrm{Y}$ como ya se señaló, la Ley de Propiedad Intelectual chilena protege las denominadas «obras de la inteligencia». Nuestro ordenamiento, por lo tanto, protege aquellas creaciones que sean fruto del intelecto humano, dejando fuera las obras que tengan su origen en la naturaleza misma o sean producto del azar.

Que la obra protegida sea aquella proveniente de un proceso intelectual nos permite asegurar que procesos mecánicos como el escaneo de un

45. Departamento de Derechos Intelectuales de la Dibam, «Preguntas frecuentes», disponible en <http://www.dibam.cl/derechos_intelectuales/faq.asp $>$.

46. Reglamento de la Ley I7.336 sobre Propiedad Intelectual, artículo 20 letra a).

47. Código Civil, artículo 584, inciso primero.

48. Constitución Política de la República, artículo I9 número 25. 
libro no se encuentran protegidos por el derecho de autor. La persona que lleva a cabo tal procedimiento de digitalización ciertamente debe estar capacitada y debe tener conocimiento acerca de cómo funcionan los dispositivos con los que trabajará, pero dicho proceso es meramente mecánico ya que está limitado a ubicar el libro en el escáner y traspasar la imagen a un computador. Este punto se refuerza si tenemos en cuenta que actividades como el escaneo de libros pueden llevarse a cabo en la actualidad a través de máquinas especializadas que requieren una muy limitada actividad humana. ${ }^{49}$

Por lo tanto, no cualquier actividad humana da origen a creaciones intelectuales. Así también lo ha señalado Antequera Parilli, al sostener que la labor de los colaboradores o asistentes técnicos no cumple con el requisito de ser un «acto creativo». Dentro de estos colaboradores se encontrarían, por ejemplo, a los transcriptores musicales o a los correctores de pruebas (Antequera Parilli, 2007: 32).

Sin embargo, la duda surge en torno a la protección de las reproducciones fotográficas. Si bien se requiere un determinado proceso técnico, la fotografía de una obra de arte claramente es algo más complejo que el escaneo de un determinado documento. La Ley de Propiedad Intelectual protege expresamente a las fotografías, sin hacer distinción. La Ley I9.9I 4 derogó el artículo 35 de la Ley de Propiedad Intelectual, que establecía requisitos especiales para la protección de las fotografías, como indicar el nombre del fotógrafo y el año de reproducción. Tras esta modificación, las fotografías pasaron a estar protegidas bajo los requisitos genéricos que la ley establece para cualquier otra creación intelectual, sin necesidad de cumplir requisitos específicos..$^{\circ}$ Sin embargo, nuestra ley por sí misma no permite concluir si la fotografía de una obra bidimen-

49. Un ejemplo de esto es el sistema que la empresa Google utiliza para escanear libros, el cual se lleva a cabo gracias a una máquina que puede escanear páginas de libros a una gran velocidad. Véase Maurren Clements, "The Secret of Google's Book Scanning Machine Revealed», NPR.org, disponible en <http://www.npr.org/blogs/library/2009/o4/ the_granting_of_patent_7508978.html>.

50. El artículo había sido modificado anteriormente por la Ley I9.I66, del año I992, que había suprimido la frase «cuando el ejemplar de la fotografía no lleve dichos datos, podrá ser libremente reproducida». La Ley I9.9I4, que terminó por derogar el artículo 35 , buscaba acomodar las leyes chilenas a las disposiciones del Tratado de Libre Comercio firmado con Estados Unidos. 
sional en el dominio público, con el solo fin de copiarla lo más fidedignamente posible, es protegible o no. Aunque las fotografías forman parte de las obras protegidas, no es claro si ciertos tipos de fotografías —en el caso de este artículo, aquellas que son meras reproducciones de obras bidimensionales preexistentes- cumplen con el requisito de «obra de la inteligencia» $\mathrm{o}$ "creación intelectual».

Las dudas aumentan al intentar determinar a qué tipo de obra corresponde la fotografía que registra lo más fidedignamente posible una obra bidimensional. Las reproducciones, al ser copias de una determinada obra, no podrían ser protegibles a través del derecho de autor, ya que esto nos llevaría a concluir que cada ejemplar de un libro posee su propia protección. Por lo tanto, en caso de sostener que las fotografías mencionadas son dignas de protección, la única opción que nos queda es tratarlas como obras derivadas. Si se sigue esa opción, hay que tener en cuenta el artículo 9 de la Ley de Propiedad Intelectual chilena, que en su inciso segundo señala:

Cuando la obra originaria pertenezca al patrimonio cultural común, el adaptador, traductor o transformador gozará de todos los derechos que esta ley otorga sobre su versión; pero no podrá oponerse a que otros utilicen la misma obra originaria para producir versiones diferentes. ${ }^{5 \Gamma}$

El problema, como se señaló en secciones anteriores, es determinar qué elemento de la fotografía en cuestión estaría siendo protegido. Claramente la obra originaria permanecerá en el dominio público, ya que la disposición citada así lo establece. ${ }^{52}$ Entonces, ¿se estaría protegiendo el mero cambio de medio que se produce? Tal respuesta tampoco parece ser satisfactoria, debido a que implicaría aceptar el monopolio del titular sobre el medio en cuestión. Por ejemplo, la primera persona que digitalice un determinado dibujo que se encuentra en el dominio público impediría que otras personas lo digitalicen. La norma citada establece que el autor de la obra derivada «no podrá oponerse a que otros utilicen la misma obra originaria para producir versiones diferentes». Si se llegase a aceptar la protección de reproducciones fotográficas de obras en

5I. Ley 17.336, artículo 9 inciso segundo.

52. Lo mismo señala la Convención Interamericana sobre Derechos de Autor en Obras Literarias, Científicas y Artísticas, en su artículo 5 inciso segundo. 
el dominio público, tal disposición no podría ser aplicable, ya que sería imposible crear una versión diferente a la protegida, puesto que su objetivo principal es registrar lo más fielmente posible la obra fotografiada.

La protección que nuestro ordenamiento jurídico hace de las obras derivadas permite sostener que el criterio de protección se encuentra más ligado a la idea de originalidad que al de sweat of the brow. Al señalar que sólo ciertos elementos de esa obra se encuentran protegidos, la ley está reconociendo que el solo esfuerzo y trabajo invertido no bastan, sino que es necesario otro criterio, basado en las aportaciones originales que haga el autor a la obra originaria.

Al definir lo que se entiende por transformación, la ley chilena sostiene que es «todo acto de modificación de la obra, comprendida su traducción, adaptación y cualquier otra variación en su forma de la que se derive una obra diferente». ${ }^{33}$ La digitalización de una obra, cualquiera sea el método utilizado y el trabajo invertido, consiste en traspasar una obra desde un soporte material a uno digital. El mero cambio de soporte no parece satisfacer el requisito de la definición citada, ya que la expresión «obra diferente» no hace referencia a este aspecto, sino que a la identidad de la obra. Esta identidad trasciende el hecho de que la obra haya sido creada a partir de tal o cual material, o que se encuentre en un soporte físico o digital, debido a que, como se explicó al comienzo de este artículo, el derecho de autor es distinto del derecho de propiedad. Que un poema esté escrito en una hoja de papel o tallado en el tronco de un árbol no constituye una variación relevante para el derecho de autor.

La ley chilena utiliza como criterio protector el hecho de que la obra derivada sea diferente a la obra originaria, diferenciando entre este tipo de obras y las meras reproducciones. Si lo que se pretende es la protección de la digitalización de una obra determinada, sin agregar más variaciones que el solo cambio de soporte, entonces no se explica que la norma establezca definiciones, requisitos y efectos diferentes para el caso de las reproducciones y las obras derivadas.

53. Ley de Propiedad Intelectual, artículo 5, letra w). 


\section{CONCLUSIONES}

El dominio público es esencial como materia prima para la creación de nuevas obras y como elemento que asegura un mercado competitivo. La protección que otorga el derecho de autor es temporal, ya que se entiende que una vez transcurrido el período que tiene el autor para gozar de forma exclusiva de los frutos de su obra, ésta debe quedar a disposición de la sociedad, de forma libre. Sin embargo, el dominio público se ha visto amenazado por diversas conductas, siendo una de ellas el alegar la protección de reproducciones de obras que se encuentran en el dominio público. Dado que la obra originaria ya no está protegida, se sostiene que la fotografía o archivo digital en la que fue copiada constituye una nueva obra y, por lo tanto, su creador goza de derechos de autor sobre aquella reproducción.

Los fundamentos jurídicos para la protección o no de estas reproducciones se basan en dos criterios, el sweat of the brow y el requisito de originalidad. El primero, esgrimido por quienes dicen que las reproducciones están protegidas, se basa en el esfuerzo invertido para la realización de las obras, mientras que el segundo se basa en aportaciones que el autor debe realizar y que permitan diferenciarla de la obra originaria. Es necesario aclarar que la doctrina del sweat of the brow no propugna una protección de toda reproducción, sino que de aquellas que requieran un esfuerzo y habilidad mayores, como la fotografía de obras de arte. La doctrina y jurisprudencia estadounidense y española, en su mayoría, optan por el criterio de la originalidad, ya que permite determinar de forma clara cuáles son los nuevos elementos incorporados por quien creó la reproducción y, por ende, permite saber qué se está protegiendo.

Al tratar la protección de estas obras es necesario tener en cuenta además la naturaleza del objeto registrado, sea éste bidimensional o tridimensional. En el primer caso no sería posible la protección, ya que el resultado siempre será una obra lo más fidedigna posible al objeto registrado. En el caso de objetos tridimensionales hay que diferenciar el medio a través del cual se está realizando la reproducción. Si es una fotografía, por ejemplo, el resultado podrá ser protegible, ya que éste variará según las decisiones artísticas del fotógrafo y, por lo tanto, se cumpliría el requisito de la originalidad. Como la fotografía sólo capta una porción de la obra tridimensional, la decisión respecto al ángulo del cual se 
tomará la fotografía afectará el resultado. Sin embargo, la tecnología ha permitido la creación de nuevas formas de reproducción, tales como los escáneres tridimensionales, que permiten crear una copia digital del objeto tomando en cuenta aspectos como su volumen, buscando un resultado lo más parecido posible a la obra originaria. En dichos casos, el requisito de la originalidad es más difícil que se cumpla.

En Chile la respuesta sobre la protección de estas obras no es sencilla, debido a que sus normas no mencionan expresamente el requisito de la originalidad. Por lo tanto, es necesario examinar otros principios para determinar si es aconsejable optar por uno u otro camino. Estos principios corresponden al incentivo económico para crear las reproducciones y el derecho que la sociedad tiene para acceder a las obras que están en el dominio público. Aunque el incentivo económico es un factor relevante al momento de determinar si estas reproducciones se deben proteger o no, la importancia del dominio público hace concluir lo contrario, sobre todo por la posibilidad de que dicha protección permita un monopolio sobre el medio en que fue realizada la reproducción. Concluir que el mero cambio de medio permite la protección de la obra resultante podría abrir la puerta a una protección a perpetuidad y no temporal, como exigen los tratados y las leyes. También, el derecho del acceso a la cultura y la necesidad de poder acceder a las obras en el dominio público hace menos aconsejable la protección de estas versiones digitales. El dominio público no sólo permite que las obras puedan ser conocidas por la mayor cantidad de personas posible, sino que además permite una utilización sin trabas.

Además, la legislación chilena sobre derecho de autor establece que las obras protegidas son las denominadas «obras de la inteligencia», lo que permitiría inferir que quedan fuera de esta protección aquellas obras que nacen del mero azar o de la aplicación de un proceso técnico o mecánico que no requiere mayor esfuerzo intelectual. De esta forma, conductas como el escaneo de un libro o la fotografía de una pintura no constituirían "obras de la inteligencia», ya que son producto de meros procesos técnicos, lo que las diferenciaría de verdaderas obras derivadas, como la traducción de un poema o la adaptación cinematográfica de una novela. En estos últimos casos el autor de la adaptación o la traducción debe incurrir en decisiones intelectuales, como determinar qué elementos de la novela mantendrá en la versión cinematográfica o escoger alguna 
de las variadas acepciones que puede tener una palabra en el idioma al que se está traduciendo el poema. Este tipo de decisiones no se aplican en el caso de la digitalización, donde el resultado buscado pretende ser lo más parecido a la obra digitalizada.

Aunque la apropiación de obras en el dominio público es un fenómeno todavía presente a lo largo del mundo, existen ciertos proyectos de digitalización que han entendido la importancia del dominio público y hacen mención a la naturaleza de las obras que albergan. Memoria Chilena es un proyecto de la Biblioteca Nacional que se encarga, entre otras cosas, de digitalizar material de relevancia histórica para el país. Durante sus primeros años incurrió en la conducta descrita en este trabajo, al señalar que todas sus obras estaban sujetas a derecho de autor. La situación fue criticada por diversas organizaciones, como ONG Derechos Digitales, el Colegio de Bibliotecarios de Chile y Creative Commons Chile. ${ }^{54}$ Tras contactarse con los responsables del portal web, estas organizaciones lograron cambiar el mensaje relativo a los derechos de autor de estas obras, reconociendo que el carácter de las obras en el dominio público no cambia al digitalizarlas. ${ }^{55}$ Este reconocimiento es relevante, ya que permite que la sociedad tenga mayor información respecto de qué tipo de obras puede utilizar y de qué forma.

\section{REFERENCIAS}

Allan, R. J. (2007). «After Bridgeman: Copyright, Museums, and Public Domain Works of Art». University of Pennsylvania Law Review, I 55. Disponible en <https://www.law.upenn.edu/journals/lawreview/ articles/volume 5 5/issue4/Allan I 55 U.Pa.L.Rev.96r\% $282007 \% 29$. pdf $>$.

54. ONG Derechos Digitales, «Dibam se apropia del patrimonio común en su sitio web Memoria Chilena» (2007), disponible en <http://www.derechosdigitales.org/224/ dibam-recibe-protesta-de-organizaciones-civiles-por-apropiarse-del-patrimonio-comunen-su-sitio-web-memoria-chilena/>.

55. «En Memoria Chilena se pueden encontrar obras de gran valor patrimonial que ya forman parte del patrimonio cultural común. Tales creaciones pueden ser utilizadas por cualquiera, siempre que se respete la paternidad y la integridad de la obra» (Memoria Chilena, «Preguntas frecuentes», disponible en <http://www.memoriachilena.cl/602/w3article-I 23838. html $>$ ). 
Álvarez Valenzuela, Daniel (20I I). «En busca de equilibrios regulatorios: Chile y las recientes reformas al derecho de autor». Disponible en $<$ http://www.ictsd.org/downloads/20I I/I 2/en-busca-de-equilibriosregulatorios-chile-y-las-recientes-reformas-al-derecho-de-autor.pdf>

—. (s/f). «Autores en el dominio público chileno». Disponible en <http:// www.simenon.cl/autores-en-el-dominio-publico-chileno/

Antequera Parilli, Ricardo (2007). Estudios de derecho de autor y derechos afines. Madrid: Editorial Reus.

Archivos de Castilla y León (20II). "Recomendaciones para la digitalización de documentos en archivos». Disponible en <http://www. aefp.org.es/NS/Documentos/Guias-Manuales/JCYLRecomendaciones_Digitalizacion_Archivos20 I I.pdf >.

Artaza Castro, Ximena (2003). «Análisis del derecho de reproducción y comunicación pública en redes digitales, a la luz de la legislación nacional y comparada». Memoria para optar al grado de Licenciado en Ciencias Jurídicas y Sociales. Santiago: Universidad de Chile, Facultad de Derecho.

Atkinson-Bonasio, Alice (20II). "Intellectual Property in Photographs: Bridgeman Art Library, Ltd. V. Corel Corp». Disponible en $<$ http://www.alicebonasio.com/Research/PDFs/Intellectual\% 20 Property \% 2oin \% 2oPhotographs.pdf>.

Blanke, J. M. (2002). "Vincent Van Gogh, 'Sweat of the Brow', and Database Protection». American Business Law Journal, 39. Disponible en <http://ssbea.mercer.edu/blanke/ABLJvanGogh.pdf>.

Busaniche, Beatriz (20I I). «Digitalización del dominio público: Regulaciones y propuestas en relación al dominio público digital». Disponible en <http://www.bea.org.ar/wp-content/uploads/20I I/ıo/busaniche.final_.cultura.tics_.pi_.pdf $>$.

Butler, Kathleen Connolly (1998). «Keeping the World Safe from Naked-Chicks-in-Art Magnets: The Plot to Control Art Images in the Public Domain Through Copyrights in Photographic and Digital Reproductions». Hastings Communications and Entertainment Law Journal, 2I (I): 55-I 27.

Cameron, Cohn T. (2006). «In Defiance of Bridgeman: Claiming Copyright in Photographic Reproductions of Public Domain Works». Texas Intellectual Property Law Journal, I 5: 3 I-62.

Cerda, Alberto (20II). "Armonización de los derechos de autor en la 
Comunidad Andina: Hacia un nuevo régimen común». Revista Ius et Praxis, I7 (2): 23I-282. Disponible en <http://www.scielo.cl/pdf/ iusetp/vi 7n2/arto9.pdf>.

Chapman, Audrey R. (200I). «La propiedad intelectual como derecho humano (obligaciones dimanantes del apartado c) del párrafo I del Artículo I 5 del Pacto Internacional de Derechos Económicos, Sociales y Culturales)». Boletín de Derecho de Autor, I 5 (3). Ediciones Unesco. Disponible en <http://unesdoc.unesco.org/ images/oOI 2/OOI 25 5/I25505s.pdf>.

Clayton Newell, Bryce (2010). «Independent Creation and Originality in the Age of Imitated Reality: A Comparative Analysis of Copyright and Database Protection for Digital Models of Real People». Brigham Young University International Law \& Management Review, 6 (2): 97-I30. Disponible en <http://papers.ssrn.com/sol3/papers.cfm?abstract_id=I709529>.

Colombet, Claude (1997). Grandes principios del derecho de autor y los derechos conexos en el mundo: Estudio de derecho comparado. Ediciones Unesco/Cindoc.

Cooper, Tanya Assim (20II). «Corbis \& Copyright?: Is Bill Gates Trying to Corner the Market on Public Domain Art?» Intellectual Property Law Bulletin, I 6: I-43.

De la Maza Gazmuri, Íñigo (2006). "Propiedad intelectual, teorías y alternativas». En Marcos Morales (coordinador), Temas actuales de propiedad intelectual. Santiago: Editorial Lexis Nexis.

Del Campo Almuna, Paulina (2003). «Evolución del derecho de autor en Chile». Memoria para optar al grado de Licenciado en Ciencias Jurídicas y Sociales. Concepción: Universidad Católica de la Santísima Concepción, Facultad de Derecho.

Dobson, Kimberly N. (2009). "The Originality of Photographs for Purposes of Copyright Law Before and After Bridgeman Art Library, Ltd V. Corel Corp». Florida Coastal Law Review, Io: 319-347. Disponible en <https://www.fcsl.edu/sites/fcsl.edu/files/dobson.pdf $>$.

Dobusch, Leonhard (20II). "The Digital Public Domain: Relevance and Regulation». HIIG Discussion Paper Series: I-35. Disponible en $<$ http://papers.ssrn.com/sol3/papers.cfm?abstract_id=20 I I 8 I $5>$.

FICSOR, Mihaly (2003). Guía Sobre Los tratados de derecho de autor y 
derechos conexos administrados por la OMPI. Ginebra: Organización Mundial de la Propiedad Intelectual.

Hariani, Krishna y Anirudh Hariani (20II). "Analyzing 'Originality' in Copyright Law: Trascending Jurisdictional Disparity». IDEA: The Intellectual Property Law Review, 5I: 49I-5IO. Disponible en $<$ http://law.unh.edu/assets/images/uploads/publications/idea-vol 5 Ino3-krishna-hariani-anirudh-hariani.pdf $>$.

Herrera, Dina (1999). Propiedad intelectual, derechos de autor: Ley 17.336 y sus modificaciones. Santiago: Jurídica.

Hughes, Justin (20II). «The Photographer's Copyright». Cardozo Legal Studies Research Paper, 347: I-88 . Disponible en <http://papers. ssrn.com/sol3/papers.cfm?abstract_id=I93 I $220>$.

IFLA (200I). "Limitaciones y excepciones al derecho de autor y derechos afines en el entorno digital: Una perspectiva internacional de las bibliotecas». Disponible en <http://portal.unesco.org/pv_obj_cache/ pv_obj_id_40I027DI97376DDI6I2D 24F3479I322E0IB90700/filename/IFLA+esp.pdf>.

Jadue Becker, Karen (2004). «El derecho de autor en las bibliotecas y galerías virtuales de Internet». Revista Chilena de Derecho Informático, 4: 53-79. Disponible en <http://www.derechoinformatico.uchile. cl/index.php/RCHDI/article/viewArticle/ı0673>.

Kelley, Katherine L. (20II). "The Complications of Bridgeman and Copyright Misuse». Art Documentation: Journal of the Art Libraries Society of North America, 30 (2): 38 -42. Disponible en <http://www. jstor.org/stable/4I 244063>.

Larraguibel, Santiago (I979). Derecho de autor y propiedad industrial: Nuevas disposiciones constitucionales. Santiago: Jurídica.

Lessig, Lawrence (2005). Cultura libre: Cómo los grandes medios usan la tecnología y las leyes para encerrar la cultura y controlar la creatividad. Santiago: Lom Ediciones.

Lipszyc, Delia (2005). Derecho de autor y derechos conexos. Buenos Aires: Unesco, Cerlalc y Zavalia.

MÁrquez Robledo, Santiago (2004). «Principios generales del derecho de autor». Tesis para optar al título de abogado. Bogotá, Pontificia Universidad Javierana. Disponible en <http://www.javeriana.edu.co/ biblos/tesis/derecho/dere6/definitiva/tesis23.pdf $>$. 
Matz, Robert C. (2000). «Public Domain Works of Art: Bridgeman Art Library, Ltd. V. Corel Corp». Berkeley Technology Law Journal, I 5 (I): $3-23$.

Mazzone, Jason (2006). "Copyfraud». New York University Law Review, 8I: I026-I Iо०. Disponible en <http://papers.ssrn.com/sol3/papers.cfm?abstract_id $=787244>$.

Moeller, Erik (2009). "Protecting the public domain and sharing our cultural heritage». Wikimedia blog. Disponible en <http://blog.wikimedia.org/2009/07/I 6/protecting-the-publicdomain-and-sharing-our-cultural-heritage/>.

Nimmer, David (200I). "Copyright in the Dead Sea Scrolls: Authorship and Originality». Houston Law Review, 38 (I): I-222. Disponible en <http://www.houstonlawreview.org/archive/downloads/38-I_pdf/ hlr38pi.pdf $>$.

Petris, Raquel H. (2003). «Digitalización, compresión y descompresión de videos para aplicación informática en entorno multimedia». Disponible en <http://www.unne.edu.ar/unnevieja/Web/cyt/cyt/2003/ comunicaciones/o8-Exactas/E-oo6.pdf>.

Puchi Zurita, Rodrigo (2006). «Protección jurídica de los programas de ordenador». En Marcos Morales (coordinador), Temas actuales de propiedad intelectual. Santiago: Lexis Nexis.

Real Márquez, Montserrat (200I). «El requisito de la originalidad en los derechos de autor». University of Alicante Intellectual Property \& Information Technology, I-I 5. Disponible en <http://www.uaipit. com/files/publicaciones/000000 I974_La \% 20originalidad-Art-uaipit2.pdf $>$.

Ribera Blanes, Begoña (2002). El derecho de reproducción en la propiedad intelectual. Madrid: Dykinson.

Ruiz Gallardo, Claudio (2008). «Hacia una dogmática para el acceso en Chile». En Carlos Cerda (editor), Acceso a la cultura y derechos de autor: Excepciones y limitaciones al derecho de autor. Santiago: Lom Ediciones. Disponible en <http://www.derechosdigitales.org/wp-content/uploads/libro-acceso-a-la-cultura-y-derechos-de-autor.pdf>.

-. (2010). Guías legales para bibliotecarios. Santiago: ONG Derechos Digitales.

Scassa, Teresa (2006). "Original Facts: Skill, Judgment, and the Public Domain». McGill Law Journal, 5I (2): 253-278. Disponible en 
<http://lawjournal.mcgill.ca/userfiles/other/6736036-I224868339_ Scassa.pdf>.

Schmitz Vaccaro, Christian (2006). «Propiedad industrial y derecho de autor ¿Una división vigente?» En Marcos Morales (coordinador), Temas actuales de propiedad intelectual. Santiago: Lexis Nexis.

-. (2009). «Propiedad intelectual, dominio público y equilibrio de intereses». Revista Chilena de Derecho, 36 (2): 343-367. Disponible en <http://www.scielo.cl/pdf/rchilder/v36n2/arto6.pdf>.

Tactuk Retif, Aurora (2009). «El derecho de transformación: Especial referencia a la parodia». Getafe: Universidad Carlos III de Madrid. Disponible en <http://e-archivo.uc3m.es/bitstream/ıoo I6/7355/I/aurora_tactuk_tesis.pdf $>$.

U. S. Copyright Office (I998). «Policy Decision on Copyrightability of Digitized Typefaces». Volumen 53 (I89): 38 I I0-38 I I3. Disponible en <http://www.copyright.gov/history/mls/ML-393.pdf>.

Unesco (20I0). "The ABC of Copyright». Disponible en <http:// www.unesco.org/pv_obj_cache/pv_obj_id_e9c4ci $8 \mathrm{ddd} 7 \mathrm{c} 7 \mathrm{c} 77$ 368dode4bc2b9b7840259boo/filename/abc_copyright_en.pdf>.

Vega Jaramillo, Alfredo (20io). Manual de derecho de autor. Colombia: Dirección Nacional de Derecho de Autor de Colombia. Disponible en <http://www.derechodeautor.gov.co/documents/IOI8I/33I998/ Cartilla+derecho+de+autor+\% 28Alfredo+Vega \% 29.pdf $/>$.

\section{SOBRE EL AUTOR}

Nicolás Bello Lagos es Licenciado en Ciencias Jurídicas y Sociales por la Universidad de Chile. El presente artículo es una versión de su memoria para optar a dicha licenciatura. Su correo electrónico es $<$ ngbellol@gmail.com> y su dirección postal es 23 Norte 933, block B, depto 2I, Viña del Mar, Chile.

Este trabajo fue recibido el 9 de junio de 2014 y aprobado el 5 de noviembre de 2014 . 
